\title{
An Evaluation of Marine Boundary Layer Cloud Property Simulations in the Community Atmosphere Model Using Satellite Observations: Conventional Subgrid Parameterization versus CLUBB
}

\author{
HUA SONG \\ Joint Center for Earth Systems Technology, University of Maryland, Baltimore County, Baltimore, Maryland \\ ZHIBO ZHANG \\ Joint Center for Earth Systems Technology, and Physics Department, University of Maryland, Baltimore County, \\ Baltimore, Maryland \\ Po-Lun Ma AND STEVEn J. GHAN \\ Atmospheric Sciences and Global Change Division, Pacific Northwest National Laboratory, Richland, Washington \\ MINGHUAI WANG \\ Institute for Climate and Global Change Research, and School of Atmospheric Sciences, Nanjing University, \\ Nanjing, China
}

(Manuscript received 26 April 2017, in final form 17 November 2017)

\begin{abstract}
This paper presents a satellite-observation-based evaluation of the marine boundary layer (MBL) cloud properties from two Community Atmosphere Model, version 5 (CAM5), simulations, one with the standard parameterization schemes (CAM5-Base) and the other with the Cloud Layers Unified by Binormals scheme (CAM5-CLUBB). When comparing the direct model outputs, the authors find that CAM5-CLUBB produces more MBL clouds, a smoother transition from stratocumulus to cumulus, and a tighter correlation between in-cloud water and cloud fraction than CAM5-Base. In the model-to-observation comparison using the COSP satellite simulators, the authors find that both simulations capture the main features and spatial patterns of the observed cloud fraction from MODIS and shortwave cloud radiative forcing (SWCF) from CERES. However, CAM5-CLUBB suffers more than CAM5-Base from a problem that can be best summarized as "undetectable" clouds (i.e., a significant fraction of simulated MBL clouds are thinner than the MODIS detection threshold). This issue leads to a smaller COSP-MODIS cloud fraction and a weaker SWCF in CAM5-CLUBB than the observations and also CAM5-Base in the tropical descending regions. Finally, the authors compare modeled radar reflectivity with CloudSat observations and find that both simulations, especially CAM5-CLUBB, suffer from an excessive drizzle problem. Further analysis reveals that the subgrid precipitation enhancement factors in CAM5-CLUBB are unrealistically large, which makes MBL clouds precipitate too excessively, and in turn results in too many undetectable thin clouds.
\end{abstract}

Supplemental information related to this paper is available at the Journals Online website: https://doi.org/10.1175/ JCLI-D-17-0277.s1.

Corresponding author: Dr. Zhibo Zhang, zhibo.zhang@umbc. edu

\section{Introduction}

Marine boundary layer (MBL) clouds cover about 1/5 of the ocean surface and serve as a strong modulator of the radiative energy budget of the earth-atmosphere system (Klein and Hartmann 1993; Wood 2012). Located in the boundary layer, MBL clouds are especially susceptible to aerosol microphysical effects (Coakley and Walsh 2002; Ackerman et al. 2000). For these reasons, a realistic representation of MBL clouds in the 
general circulation models (GCMs) is critical for an accurate and reliable climate projection.

Because many physical processes related to MBL clouds, such as turbulence and convection, occur at spatial scales much smaller than the typical grid size of GCMs $(\sim 100 \mathrm{~km})$, subgrid cloud parameterization schemes are needed to connect subgrid cloud processes with resolved grid-level variables. In most current GCMs, cloud-related physical processes are usually categorized into several regimes, each controlled by a separate subgrid parameterization scheme. For example, the Community Atmosphere Model, version 5 (CAM5), categorizes subgrid parameterization schemes into deep convection, shallow convection, planetary boundary layer (PBL), and cloud macrophysics (Neale et al. 2010; Park et al. 2014). Such a conventional framework is conceptually simple. Cloud simulation in GCMs often improves significantly when individual cloud parameterization schemes are improved (Kay et al. 2012; Pincus et al. 2012). However, a bottleneck for this conventional framework is that in nature there is often no clear and discrete separation of cloud physics regimes. As a result, conventional GCMs often have difficulty in simulating a smooth and continuous stratocumulus $(\mathrm{Sc})$ to cumulus $(\mathrm{Cu})$ cloud transition (Guo et al. 2014; Kubar et al. 2015; Bogenschutz et al. 2013). This is referred to as the Sc-to-Cu transition (STCT) problem hereafter. Another long-lasting problem is that GCMs based on conventional subgrid parameterization schemes tend to generate too few MBL clouds and at the same time overestimate the brightness of the clouds. The two biases tend to counterbalance each other in radiative transfer calculations. This is the well-known "too few, too bright" problem (Webb et al. 2001; Zhang et al. 2005). Although significant progress has been made recently, it is still a common problem in GCMs, including CAM5 (Nam et al. 2012; Klein et al. 2013).

Over the past few decades, substantial efforts have been made to improve the subgrid cloud parameterization schemes in GCMs. A noteworthy achievement is the novel subgrid cloud scheme called Cloud Layers Unified by Binormals (CLUBB) (Golaz et al. 2002a,b; Larson et al. 2002). CLUBB is a partial third-order turbulence closure scheme that utilizes a doubleGaussian joint probability density function (PDF) to model the variance and covariance of subgrid vertical velocity, temperature, and moisture. A major promise of CLUBB is that by varying the shape of the joint PDF it can represent various cloud regimes (e.g., PBL and shallow convection) in the same framework and thereby provide a unified subgrid cloud physics. For example, in the conventional framework of CAM5, cloud fraction and cloud condensate are often treated by different schemes separately and independently. In CLUBB, the cloud fraction and cloud condensate are simultaneously diagnosed from the joint PDF of temperature and moisture in a physically consistent manner. Another appealing feature of CLUBB is that, not only does it provide the mean values of cloud properties (e.g., grid-mean cloud liquid water content), but it also provides the subgrid variances of these properties diagnosed from the joint PDF. These are highly useful information for simulating the nonlinear processes in the model, such as radiation and cloud microphysics. Because of these apparent advantages of CLUBB over the conventional framework, it has been implemented in several major GCMs including CAM5 (Bogenschutz et al. 2013) and the GFDL Atmospheric Model, version 3 (AM3; Guo et al. 2014, 2015).

Although CLUBB is considered as a major recent advancement in subgrid parameterization, it is relatively new and mathematically complicated. Substantial efforts are being made to better integrate it with the host model and realize its full potential (e.g., Larson and Schanen 2013). Thus, in parallel to model development, efforts are also being made to evaluate the performance of CLUBB. Bogenschutz et al. (2013) found that CLUBB improves several aspects of cloud simulations in CAM5, chief among which is a much smoother STCT. Similarly, Kubar et al. (2015) also found that CLUBB helps simulate more realistic cloud fraction distribution in the northeastern and southeastern Pacific subsidence regions than the conventional parameterization schemes. Recent studies also expose some potential problems of CLUBB. A recent study by Zheng et al. (2016) used a short-term hindcast approach and compared the MBL cloud simulations in the CAM5CLUBB with the ground-based cloud measurements from the Atmospheric Radiation Measurement (ARM) Program. They found that although CLUBB helps increase the MBL cloud fraction, the in-cloud water from CLUBB is biased too low. As a result, MBL clouds are not bright enough in comparison with observations, leading to a weaker cloud radiative forcing in the model.

Satellite observations are invaluable for evaluating GCM simulations on global to regional scales. In particular, instruments on NASA's A-Train satellite constellation provide unprecedentedly rich information on cloud properties for GCM evaluation. The Clouds and the Earth's Radiant Energy System (CERES) provides radiation measurements at the top of the atmosphere (TOA), as well as cloud radiative forcing estimation (Loeb et al. 2012). The Moderate Resolution Imaging Spectroradiometer (MODIS) provides a variety of cloud property retrievals, including cloud fraction, cloud optical depth, and cloud droplet effective radius (Platnick et al. 2017). Perhaps, the most unique satellite 
instruments in the A-Train are the two active sensorsthe Cloud-Aerosol Lidar and Infrared Pathfinder Satellite Observations (CALIPSO) (Winker et al. 2009) and CloudSat (Stephens et al. 2002). Together they depict a three-dimensional distribution of cloud and aerosols that is impossible for passive sensors. What makes the A-Train cloud observations even more useful is that the observations are collocated and therefore can be easily combined and used together to achieve a comprehensive perspective. For these reasons, cloud observations from A-Train instruments have been used alone or in combination with one another in numerous previous studies for evaluation of cloud simulations in conventional GCMs (e.g., Zhang et al. 2010; Jiang et al. 2012; Kay et al. 2012; Pincus et al. 2012; Lebsock et al. 2013).

To assess the performance of CLUBB versus the conventional parameterization schemes, we present here an evaluation study of MBL cloud simulations in CAM5-CLUBB in comparison with those in CAM5Base (i.e., CAM5 with standard physical schemes) using satellite observations from the A-Train. In the light of previous strides, we pay special attention to three questions in the evaluation: Does CAM5-CLUBB simulate a smoother STCT in comparison with CAM5Base? Does CLUBB help alleviate the too few, too bright problem (e.g., consistency between cloud fraction and incloud microphysical properties)? Does CLUBB simulate better warm rain processes in MBL clouds? The rest of the paper is organized as follows: Section 2 describes the model and observation data used in this study. Results are presented in section 3 and section 4. Finally, section 5 provides general conclusions and remarks for future work.

\section{Description of model and satellite observations}

\section{a. Models}

Both the CAM5-Base and CAM5-CLUBB use the finite-volume dynamical core at $1.9^{\circ}$ latitude $\times 2.5^{\circ}$ longitude resolution with 30 vertical levels and 1800-s time step. The simulations are run in a "constrained meteorology" configuration (Ma et al. 2013, 2015) to facilitate model evaluation against observations, in which the model winds are nudged toward the ModernEra Retrospective Analysis for Research Applications (MERRA) with a relaxation time scale of $6 \mathrm{~h}$ (Zhang et al. 2014). The model simulations are performed from September 2008 to December 2010 (28 months). The last 24 months (January 2009-December 2010) of the simulations are used for analysis, which corresponds to the Clouds, Aerosol, and Precipitation in the Marine Boundary Layer (CAP-MBL) field campaign conducted by the ARM Program of the Department of Energy in the Azores region (Wood et al. 2015; Zheng et al. 2016). Although this study focuses on evaluation using satellite observations, we plan to extend the evaluation using ground-based retrievals from CAP-MBL campaign in follow-up studies.

Table 1 lists the major physical parameterization schemes used in two simulations. The CAM5-Base employs the University of Washington shallow convection scheme (UWSC; Park and Bretherton 2009), the Park cloud macrophysics (Park et al. 2014), and the University of Washington moist turbulent (UWMT) PBL scheme (Bretherton and Park 2009). In CAM5CLUBB, the UWSC, Park macrophysics (excluding ice macrophysics), and UWMT are replaced and unified by the CLUBB scheme (Golaz et al. 2002a,b). The details of how the CLUBB scheme is implemented in the CAM5.3 and coupled with other parameterizations are discussed in Bogenschutz et al. (2012, 2013).

Although cloud fraction is diagnosed in both CAM5Base and CAM5-CLUBB, the detailed process is quite different. Both diagnostic schemes partition cloud fraction into two broad types: convective and stratiform. The total cloud fraction is the sum of the two. In CAM5Base, the total convective cloud fraction is further divided into deep and shallow convective cloud fractions. Detailed information about the calculation of cloud fraction for different clouds (e.g., deep convective, shallow convective, liquid stratiform, and ice stratiform) can be found in previous studies (Xu and Krueger 1991; Park et al. 2014; Gettelman et al. 2010). Different from CAM5-Base, the CAM5-CLUBB handles shallow convective cloud and liquid stratiform cloud together by CLUBB, in which cloud fraction and in-cloud water are diagnosed from the assumed joint double-Gaussian PDF (Bogenschutz et al. 2012). The liquid cloud fraction may include shallow $\mathrm{Cu}$, liquid stratus, and $\mathrm{Sc}$, but it is simply labeled as stratiform cloud fraction in the CAM5-CLUBB output.

Another noteworthy difference is that CAM5-Base and CAM5-CLUBB make different assumptions of the subgrid cloud water distribution in their calculations of precipitation rates. The warm rain processes in MBL clouds (e.g., autoconversion and accretion) are nonlinear functions of cloud water content, and, as such, they depend on not only grid-mean cloud water but also the subgrid cloud water distribution (Khairoutdinov and Kogan 2000; Seifert and Beheng 2006; Morrison and Gettelman 2008, hereafter MG08). In CAM5-Base, because of the lack of subgrid cloud information, the MG08 cloud microphysics scheme assumes a gamma distribution with a fixed inverse relative variance $\nu$ for subgrid cloud water distribution, which inevitably falls short of the complexity of real clouds. The fact that 
TABLE 1. Physical schemes used in two CAM5 simulations.

\begin{tabular}{|c|c|c|}
\hline Physics & CAM5-Base & CAM5-CLUBB \\
\hline Deep convection & $\begin{array}{l}\text { Modified Zhang-McFarlane } \\
\quad(\text { ZM; Zhang-McFarlane 1995; Neale et al. 2010) }\end{array}$ & Modified ZM (Zhang-McFarlane 1995; Neale et al. 2010) \\
\hline Shallow convection & UWSC (Park and Bretherton 2009) & CLUBB (Bogenschutz et al. 2012) \\
\hline PBL & UWMT (Bretherton and Park 2009) & CLUBB (Bogenschutz et al. 2012) \\
\hline Cloud macrophysics & Park (Neale et al. 2010) & CLUBB (Bogenschutz et al. 2012) \\
\hline Cloud microphysics & $\begin{array}{l}\text { 2-moment prognostic (Morrison and } \\
\text { Gettelman 2008) }\end{array}$ & 2-moment prognostic (Morrison and Gettelman 2008) \\
\hline Radiation & $\begin{array}{l}\text { Rapid Radiative Transfer Model for } \\
\text { GCMs (RRTMG) (Iacono et al. 2008) }\end{array}$ & RRTMG (Iacono et al. 2008) \\
\hline
\end{tabular}

CLUBB provides explicit subgrid cloud water distribution seems to offer an excellent opportunity to overcome this obstacle. However, seizing this opportunity requires a new modeling framework that enables fundamental coupling of CLUBB with cloud microphysics scheme (Larson and Schanen 2013). While the new coupling framework is being developed and tested, currently CLUBB is coupled with MG08 in a very simple manner in CAM5-CLUBB. Instead of using the full PDF, the MG08 uses only the subgrid cloud water variance from CLUBB to determine the parameters of the gamma distribution, namely, the inverse relative variance $\nu$ (Guo et al. 2014). On one hand, a flexible $\nu$ value diagnosed from CLUBB allows temporal and spatial variations of the subgrid distribution of cloud water associated with different cloud regimes to impact cloud microphysics. However, on the other hand, it is important to note that as it stands now there is a discrepancy between MG08 and CLUBB in terms of the assumed form of subgrid cloud water distribution; MG08 assumes gamma distribution while CLUBB assumes double-Gaussian distribution.

\section{b. $C O S P$}

To facilitate comparisons between satellite observations and model simulations, the Cloud Feedback Model Intercomparison Project (CFMIP) Observation Simulator Package (COSP) that uses simplified synthetic retrieval processes to mimic what would be the satellite cloud observations given the GCM simulated cloud fields (Bodas-Salcedo et al. 2011). COSP has three major parts, each controlling a step of the synthetic retrieval process: 1) the subcolumn generator of COSP first distributes the grid-mean cloud and precipitation properties from GCM into the so-called subcolumns that are conceptually similar to pixels in satellite remote sensing, 2) the satellite simulators simulate the direct measurements (e.g., CloudSat radar reflectivity and CALIOP backscatter) and retrieval products (e.g., MODIS cloud optical thickness and effective radius) for each subcolumn using highly simplified radiative transfer and retrieval schemes, 3) the aggregation scheme averages the subcolumn simulations back to grid level to obtain temporal-spatial averages that are comparable with aggregated satellite products (e.g., MODIS level-3 gridded monthly mean products). Currently, COSP version 1.4 provides cloud measurement and retrievals simulations for a variety of satellite sensors. In this study, we evaluate the modeled cloud fraction, cloud liquid water path, cloud optical thickness $\tau$, and cloud effective radius $r_{e}$ through comparisons between COSP-MODIS simulations and MODIS observations. In addition, we will evaluate the warm rain processes in the model through comparisons of radar reflectivity statistics from COSP-CloudSat simulator with CloudSat observations. The simulator outputs are produced from 6-hourly calculations, and the number of subcolumns used here is 70 . To derive the probability of precipitation, we made some simple in-house modifications in COSP version 1.4 to write out the MODIS and CloudSat simulations for every subcolumn. This allows us to derive the joint statistics of COSP-MODIS and COSP-CloudSat simulations and compare them with those derived from collocated MODIS and CloudSat level-2 products.

It is important to point out here a couple of technical details of the COSP simulator (version 1.4) used in this study so that we can better explain the evaluation results later. First, as a passive sensor, MODIS is usually unable to detect subvisible clouds with optical thickness smaller than 0.3 (Ackerman et al. 1998). To mimic this detection limitation of MODIS, the COSP-MODIS simulator uses a minimum detectable threshold of $\tau\left(\tau_{\min }=0.3\right)$ to remove those subvisible clouds that are probably undetected by MODIS instruments (Pincus et al. 2012). Second, the current COSP subcolumn generator is very simple. It accounts only for the subgrid variability of the types of hydrometeors and ignores the variability of mass and microphysics within each hydrometeor type.

\section{c. Satellite data}

In this study, we use the cloud and radiation measurements from the A-Train satellite sensors, namely, MODIS, CALIPSO, CloudSat, and CERES, for modelto-observation comparison. The newly released collection 
6 (C6) Aqua-MODIS cloud products (Platnick et al. 2017) are used to evaluate cloud fraction, cloud optical thickness, and cloud droplet effective radius. There is a major change explained below from the previous C5 to the current C6 MODIS cloud products that is especially important to our MBL cloud evaluation. MODIS performs cloud property retrievals at $1-\mathrm{km}$ resolution. At this resolution, a significant fraction $(\sim 30 \%)$ of cloudy pixels, mostly cloud edges, are likely to be partly cloudy (PCL). It is known that cloud property retrievals for these PCL pixels suffer from greater uncertainty than overcast pixels, owing to surface contamination and stronger subpixel inhomogeneity. In the previous C5 product, PCL pixels are excluded in the final product (Cho et al. 2015). A major change in the C6 MODIS algorithm is that the cloud property retrievals for the PCL pixels are reported in the final product, albeit separately from the overcast pixels to remind users of the likely larger uncertainty associated with the PCL pixels. Most previous studies used the C5 MODIS cloud product to evaluate GCMs (Kay et al. 2012; Pincus et al. 2012; Bodas-Salcedo et al. 2011). In this study, we will discuss the impacts of including PCL pixels on GCM evaluation. We also employ the CALIPSO version-3 level-2 1-km (horizontal resolution) cloud layer product (CAL_LID_L2_01kmCLay). CALIPSO cloud profiles are obtained from the backscattered light generated by a dual-wavelength (532 and $1064 \mathrm{~nm}$ ) polarization sensitive lidar, which is capable of detecting clouds with an optical depth of 0.01 or less and optical depths as large as 5 (Winker et al. 2010). We use the feature classification flags reported in the CALIPSO dataset to identify cloud layers and calculate cloud fraction.

CloudSat is another A-Train instrument that is especially useful for cloud studies. The direct measurement of CloudSat is the vertical profile of $94-\mathrm{GHz}$ radar reflectivity caused cloud and hydrometeor particles (i.e., 2B-GEOPROF product), from which other information such as vertical distribution of clouds and precipitation can be derived. For MBL cloud studies, CloudSat provides valuable information on the warm rain process that cannot be achieved by a passive sensor like MODIS. The CloudSat 2B-GEOPROF product (Marchand et al. 2008) is used for cloud vertical structure, radar reflectivity, and identification of precipitation in MBL clouds. To prepare for the comparison of joint statistics, we collocated five years (2006-10) of pixel-level (i.e., level-2) MODIS, CALIPSO, and CloudSat observations using the collocation scheme developed in Cho et al. (2008). This collocated MODIS-CALIPSO-CloudSat dataset has been used in Cho et al. (2015) for understanding uncertainties in MODIS cloud products. Because of the low sampling rate of CloudSat, we used five years (2006-10) of observations, in comparison with the 2-yr model simulation (2009-10), to obtain enough statistics. A sensitivity study indicates that the interannual variability of MBL clouds is much smaller than the model-to-observation differences.

In addition to MODIS, CALIPSO, and CloudSat, we also use the shortwave cloud radiative forcing (SWCF) data derived from the CERES Energy Balanced and Filled at the top of atmosphere (EBAF-TOA) edition 2.8 (Ed2.8) dataset (Loeb et al. 2012; Doelling et al. 2013).

In this study, we focus on the tropical and subtropical regions between $45^{\circ} \mathrm{S}$ and $45^{\circ} \mathrm{N}$ (loosely referred to as "tropical and subtropical region"), where most stratocumulus and cumulus regimes are found. In addition, satellite observations, namely MODIS, may have large uncertainties at high latitudes due to low solar zenith angles (Kato and Marshak 2009; Grosvenor and Wood 2014; Cho et al. 2015).

\section{Evaluation of cloud properties and cloud radiative effects}

\section{a. Model-to-model comparison of CAM5-Base and CAM5-CLUBB}

We start the evaluation with cloud fraction. Before proceeding to the comparisons between model simulations with MODIS observations, we first compare the direct model outputs from CAM5-Base and CAM5CLUBB. This is a necessary and important step to understand the impacts of CLUBB on modeled cloud fields, without the complications of COSP. The annual mean total and low cloud fractions from the CAM5Base and CAM5-CLUBB simulations are compared in Fig. 1. Although similar to CAM5-Base in the largescale pattern, CAM5-CLUBB produces larger cloud fractions in the major MBL cloud regions (except the near-coastal areas), including the subtropical south Indian Ocean, southeastern Pacific, tropical South Atlantic, and subtropical North Pacific. Another noteworthy point is that, compared to CAM5-Base the CAM5-CLUBB seems to produce a smoother STCT, for example, in the northeastern and southeastern Pacific, which is aligned with several recent studies that also found improvement of STCT by CLUBB (e.g., Bogenschutz et al. 2013; Kubar et al. 2015; Wang et al. 2015). The differences in total cloud fraction between CAM5CLUBB and CAM5-Base are closely correlated to their differences in low cloud fraction (right panels in Fig. 1), suggesting that cloud fraction differences are mainly the results of using different warm cloud parameterization schemes. In contrast to the increase of low cloud fraction in the MBL cloud regimes, there is a 

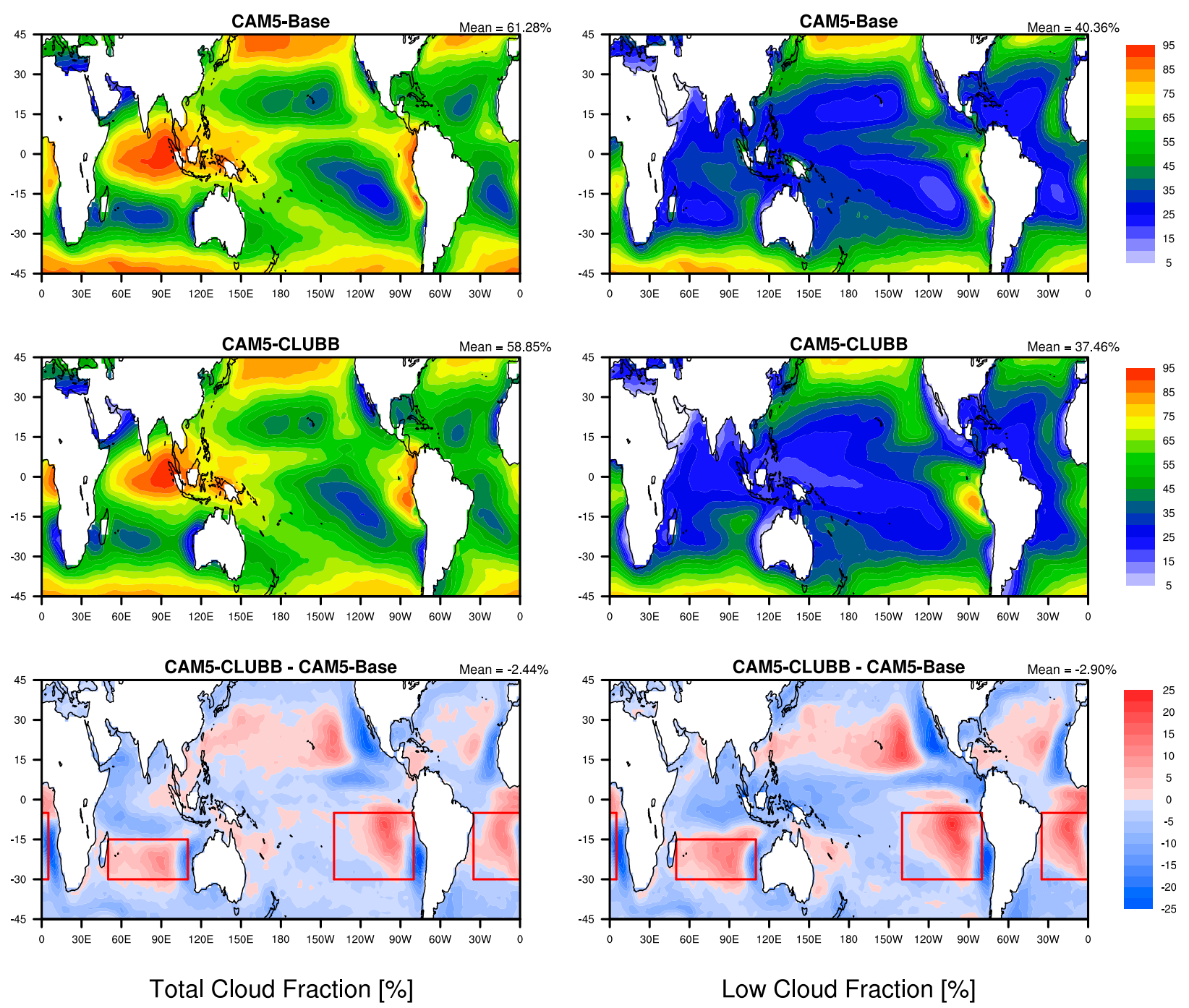

FIG. 1. (left) Total cloud fraction (\%) and (right) low cloud fraction (\%) averaged over the 2-yr simulation of (top) CAM5-Base, (middle) CAM5-CLUBB, and (bottom) the difference between the two.

general and significant decrease of low clouds over the tropical convective regions (e.g., ITCZ and west Pacific warm pool), which counterbalances the increase of MBL clouds and amounts to an overall slight decrease of tropical and subtropical mean low and total cloud fractions in CAM5-CLUBB (37.5\%, and 58.9\%, respectively) compared to CAM5-Base (40.4\% and $61.3 \%$, respectively).

Next, we will take a closer look at the MBL clouds in three oceanic regions under subsidence (e.g., red boxes in Fig. 1): south Indian Ocean $\left(30^{\circ}-15^{\circ} \mathrm{S}, 50^{\circ}-110^{\circ} \mathrm{E}\right)$, southeastern Pacific Ocean $\left(30^{\circ}-5^{\circ} \mathrm{S}, 140^{\circ}-80^{\circ} \mathrm{W}\right)$, and South Atlantic Ocean $\left(30^{\circ}-5^{\circ} \mathrm{S}, 35^{\circ} \mathrm{W}-5^{\circ} \mathrm{E}\right)$. The zonal-vertical distributions of meridional mean cloud fraction in the three MBL regions are shown in Fig. 2. In CAM5-Base (top-left panel of Fig. 2), the Sc decks are very close to the continents and dissipate quickly westward, resulting in an abrupt STCT. In CAM5CLUBB (top-right panel of Fig. 2), Sc decks are farther away from the continent and more extensive. Again, the STCT is much smoother in CAM5-CLUBB than in CAM5-Base. The results after partitioning the total clouds into deep convective clouds and other types of clouds are shown in the lower panels of Fig. 2. As aforementioned, non-deep-convective clouds in CAM5-Base include shallow convective clouds and stratiform clouds handled by the UWSC and UWMT schemes, respectively, while in CAM5-CLUBB all non-deep-convective liquid clouds are handled by the CLUBB. In CAM5-Base, stratiform low clouds dominate the eastern part of the domain and decrease abruptly westward. The shallow convective 
CAM5-Base

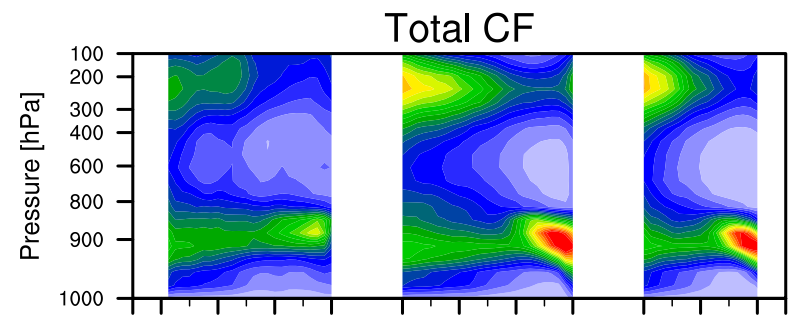

Deep Conv. CF

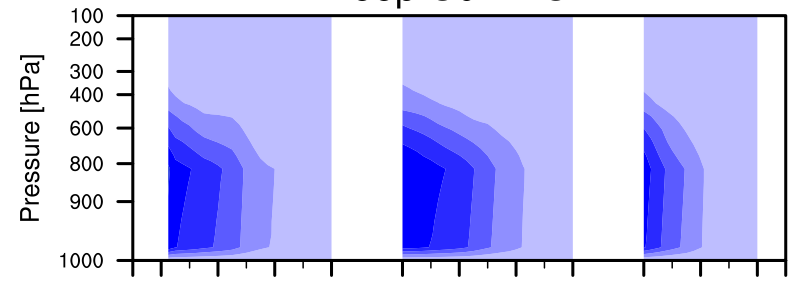

Shallow Conv. CF

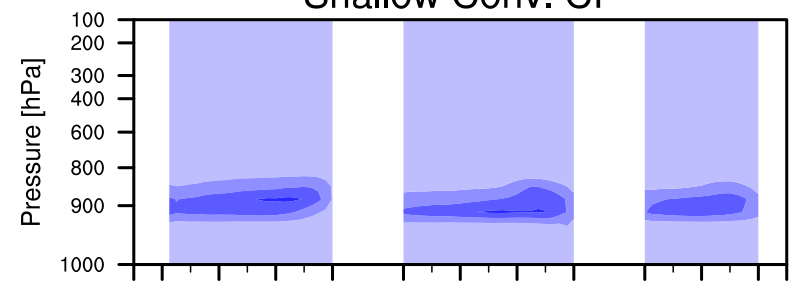

Strat. CF

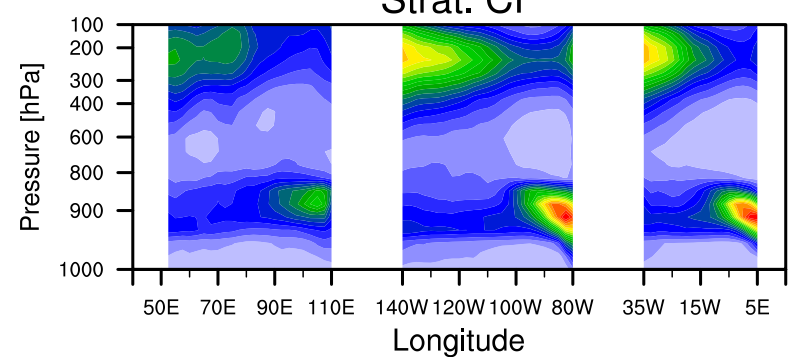

CAM5-CLUBB

Total CF

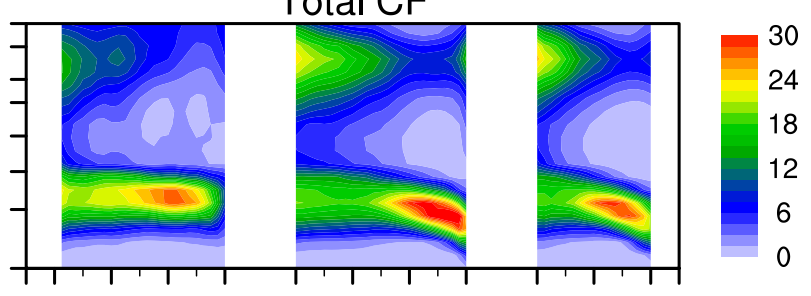

Deep Conv. CF

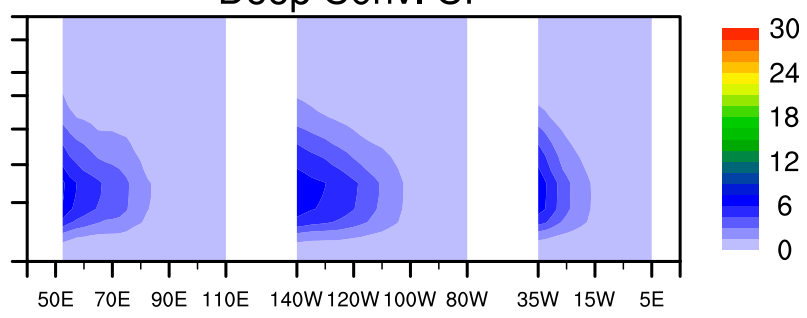

50E 70E 90E 110E 140W 120W 100W 80W 35W 15W 5E
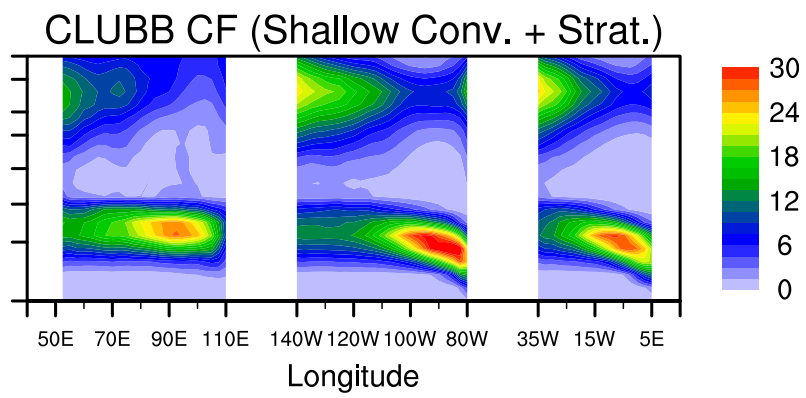

FIG. 2. Zonal-vertical distributions of meridional mean total, convective (deep and shallow in CAM5-Base, only deep convective in CAM5CLUBB), and stratiform (stratiform cloud fraction in CAM5-CLUBB includes shallow convective and stratiform cloud fractions) cloud fractions (\%) over the south Indian, southeastern Pacific, and South Atlantic Oceans in (left) CAM5-Base and (right) CAM5-CLUBB.

cloud fractions have a moderate peak in the center of the domain as expected. However, the peaks are not strong enough to compensate the sudden drop of stratiform clouds. Take the southeastern Pacific region $\left(140^{\circ}-80^{\circ} \mathrm{W}\right)$ for example. The cloud fraction generated by the PBL scheme reduces abruptly from about $30 \%$ to below $10 \%$ around $100^{\circ} \mathrm{W}$ where there are not enough convective clouds from the shallow convection scheme to compensate for the sudden drop of stratiform clouds, leading to an abrupt STCT. The partition of deep-convective and non-deep-convective clouds in CAM5-CLUBB is quite different from that in CAM5Base, with stratiform clouds dominating most of the domain. The comparison between CAM5-Base and CAM5-CLUBB in Fig. 2 clearly demonstrates the difficulty facing the conventional subgrid cloud parameterization framework (i.e., simulating a smooth STCT). Because of the unified physics, CAM5-CLUBB evidently does a better job in this regard.

The zonal-vertical distributions of meridional mean in-cloud water mixing ratio $q_{\iota}$ and cloud optical thickness $\tau$, overlaid on total cloud fraction, for the three 
CAM5-Base

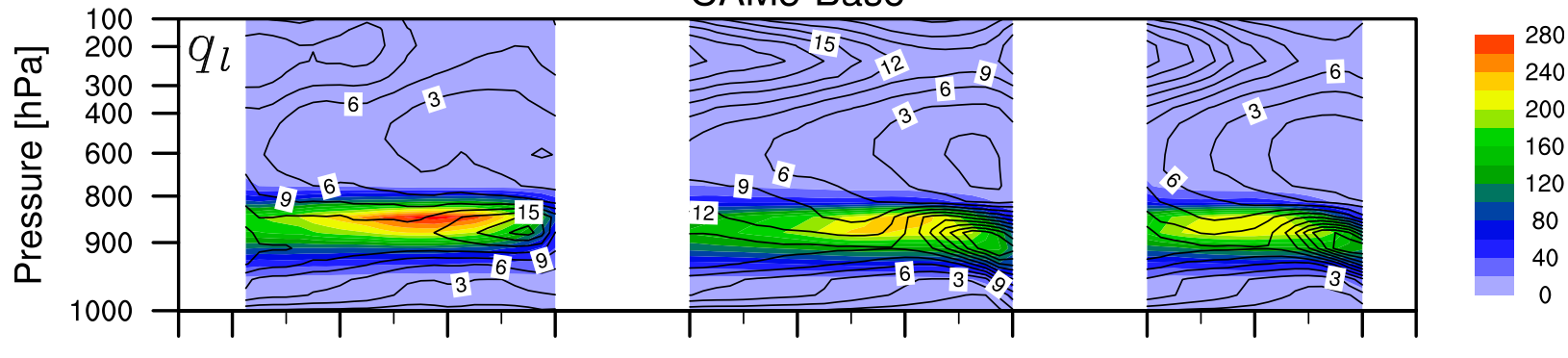

CAM5-CLUBB

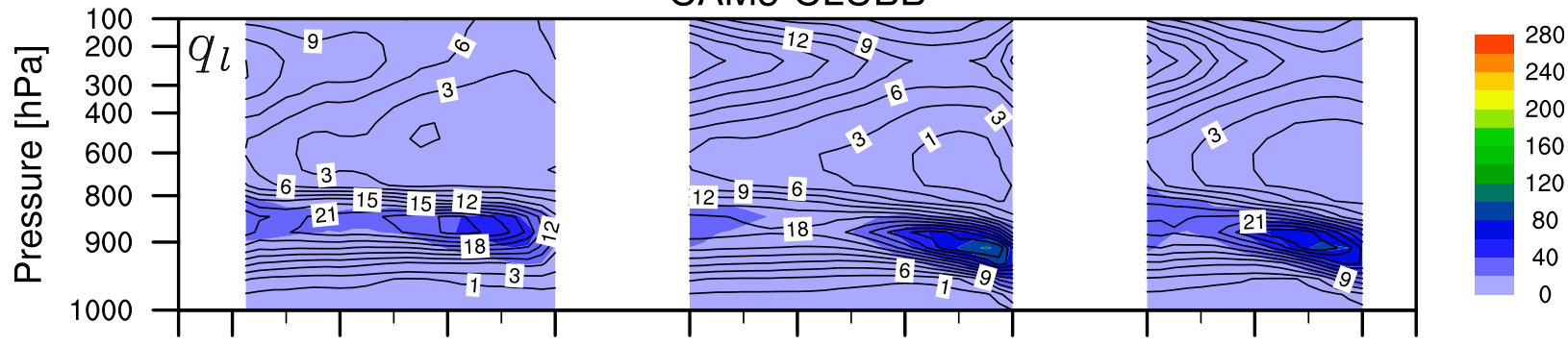

CAM5-Base

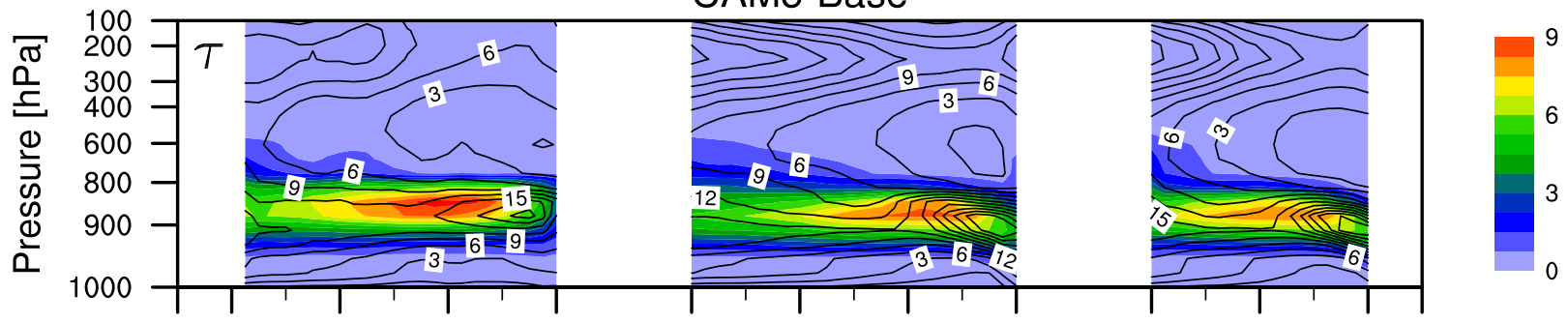

CAM5-CLUBB

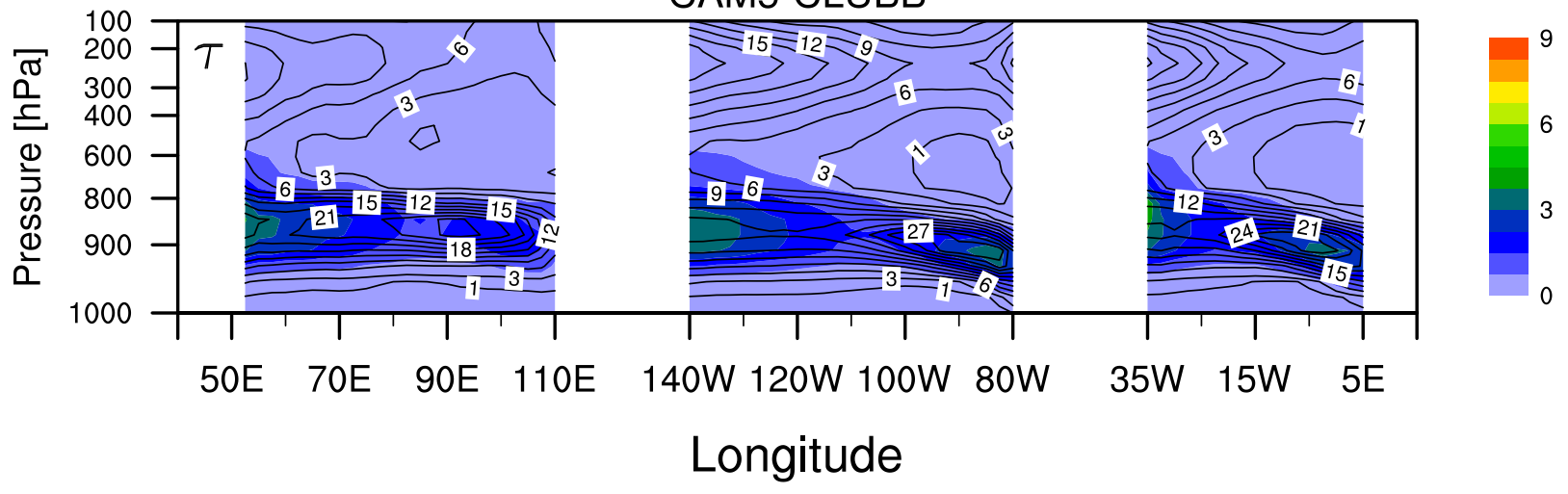

FIG. 3. Zonal-vertical distributions of (top two rows) meridional mean in-cloud water mixing ratio ( $\left.\mathrm{mg} \mathrm{kg}^{-1}\right)$ and (bottom two rows) cloud optical thickness over the south Indian, southeastern Pacific, and South Atlantic Oceans in CAM5-Base and CAM5-CLUBB. Contours are total cloud fraction (\%).

selected regions are shown in Fig. 3. One striking difference between the two simulations is that in-cloud $q_{\imath}$ and $\tau$ in CAM5-Base are almost twice as large as their counterparts in CAM5-CLUBB for MBL clouds. Interestingly, in CAM5-Base the peaks of $q_{\iota}$ and $\tau$ occur around the transition points from the $\mathrm{Sc}$ to $\mathrm{Cu}$ (e.g., around $90^{\circ} \mathrm{E}, 100^{\circ} \mathrm{W}$, and $10^{\circ} \mathrm{W}$ for the Indian, Pacific, and Atlantic Oceans, respectively), where cloud fractions are at a local minimum. This is the typical too few, too bright problem discussed in many previous studies. 

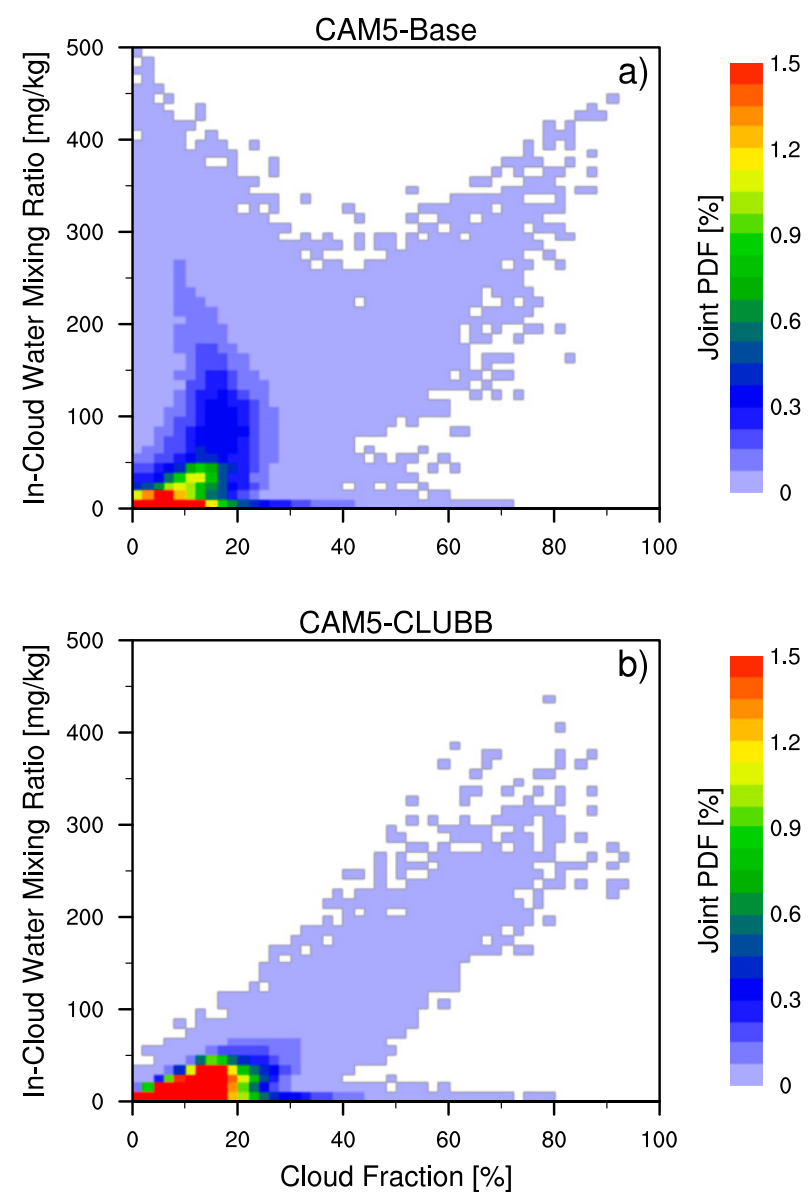

FIG. 4. Joint PDF (\%) of cloud fraction and in-cloud water mixing ratio for clouds below $600 \mathrm{hPa}$ over oceanic regions from $45^{\circ} \mathrm{S}$ to $45^{\circ} \mathrm{N}$ in (a) CAM5-Base and (b) CAM5-CLUBB for the 2-yr simulations.

That is, an underestimated cloud fraction (too few) in the model is offset by an overestimated in-cloud optical thickness (too bright) to ensure a reasonable TOA radiative energy budget (e.g., Zhang et al. 2005; Nam et al. 2012; Dolinar et al. 2015). In contrast, in CAM5CLUBB the in-cloud mixing ratio and cloud extinction are both generally correlated with cloud fraction. This is further confirmed in Fig. 4, which shows the joint PDF between grid-mean cloud fraction and $q_{\iota}$ for low clouds below $600 \mathrm{hPa}$. The joint PDF of CAM5-Base (Fig. 4a) has three branches. In one branch, $q_{\iota}$ generally increases with cloud fraction. However, in another branch, where cloud fraction is mostly below $20 \%, q_{\iota}$ shows little correlation with cloud fraction. The value of $q_{\iota}$ can be as large as $400 \mathrm{mg} \mathrm{kg}^{-1}$ for some grids with cloud fraction smaller than $10 \%$. This decoupling is probably because in CAM5-Base the subgrid schemes simulating $q_{\iota}$ (e.g., UWSC) are separate and independent from the cloud macrophysics scheme that controls the cloud fraction diagnostics. Finally, a significant fraction of grids with cloud fraction larger than $20 \%$ (up to $70 \%$ ) have nearzero in-cloud water. In the CAM5-CLUBB simulation (Fig. 4b), $q_{\iota}$ and cloud fraction are coupled more tightly. For most grids, $q_{\iota}$ tends to increase with increasing cloud fraction. Most grids with small cloud fraction tend to also have small in-cloud water. These results are aligned with the study of Zheng et al. (2016), in which they argue that the better relationship of cloud fraction to in-cloud liquid water simulated by CAM5-CLUBB is most likely due to CLUBB's consistent treatment of these variables through a PDF approach. However, similar to CAM5Base, there are significant amounts of grids in CAM5Base with near-zero $q_{\iota}$ and at the same time significant cloud fraction. In some extreme cases, a grid cell can have up to $80 \%$ cloud fraction and near-zero in-cloud water.

\section{b. Comparisons of model simulations and satellite observations through COSP}

The above comparisons of direct model outputs of cloud properties suggest that the changes by CLUBB are arguably in the right direction, although some problems still remain. However, it must be emphasized again, the above comparisons are based on the direct model outputs.

We now investigate whether the changes made by CLUBB lead to better agreement with satellite observations (i.e., a real model improvement). As shown in the top panels of Fig. 5, total cloud fractions over oceans between $45^{\circ} \mathrm{S}$ and $45^{\circ} \mathrm{N}$ derived from MODIS and CALIPSO observations are highly similar to one another. Previous studies have also found close agreement between MODIS and CALIPSO cloud-masking products, except over polar regions (Holz et al. 2008). The domain-averaged $\left(45^{\circ} \mathrm{S}-45^{\circ} \mathrm{N}\right)$ value from $C A L I P S O$ is $63.1 \%$, slightly higher than $61.5 \%$ from MODIS. This is expected because as an active sensor CALIPSO is more sensitive to optically thin clouds than MODIS. As aforementioned, MODIS has a minimum detection threshold $\tau_{\min }=0.3$. The CALIPSO detection threshold is much smaller (Vaughan et al. 2009).

The total cloud fractions from CAM5-Base and CAM5-CLUBB COSP-MODIS simulator outputs are shown in the middle panels of Fig. 5, and their differences with MODIS observations are shown in the bottom panels. The results can be analyzed from different perspectives. First of all, in comparison with MODIS observations, both CAM5-Base $(6.7 \%$ deficit $)$ and CAM5-CLUBB (15.5\% deficit) underestimate the MODIS total cloud fraction, especially in the STCT regions. More interestingly, in comparison with the direct model output in Fig. 1, cloud fraction is reduced in both CAM5-Base and CAM5-CLUBB after 

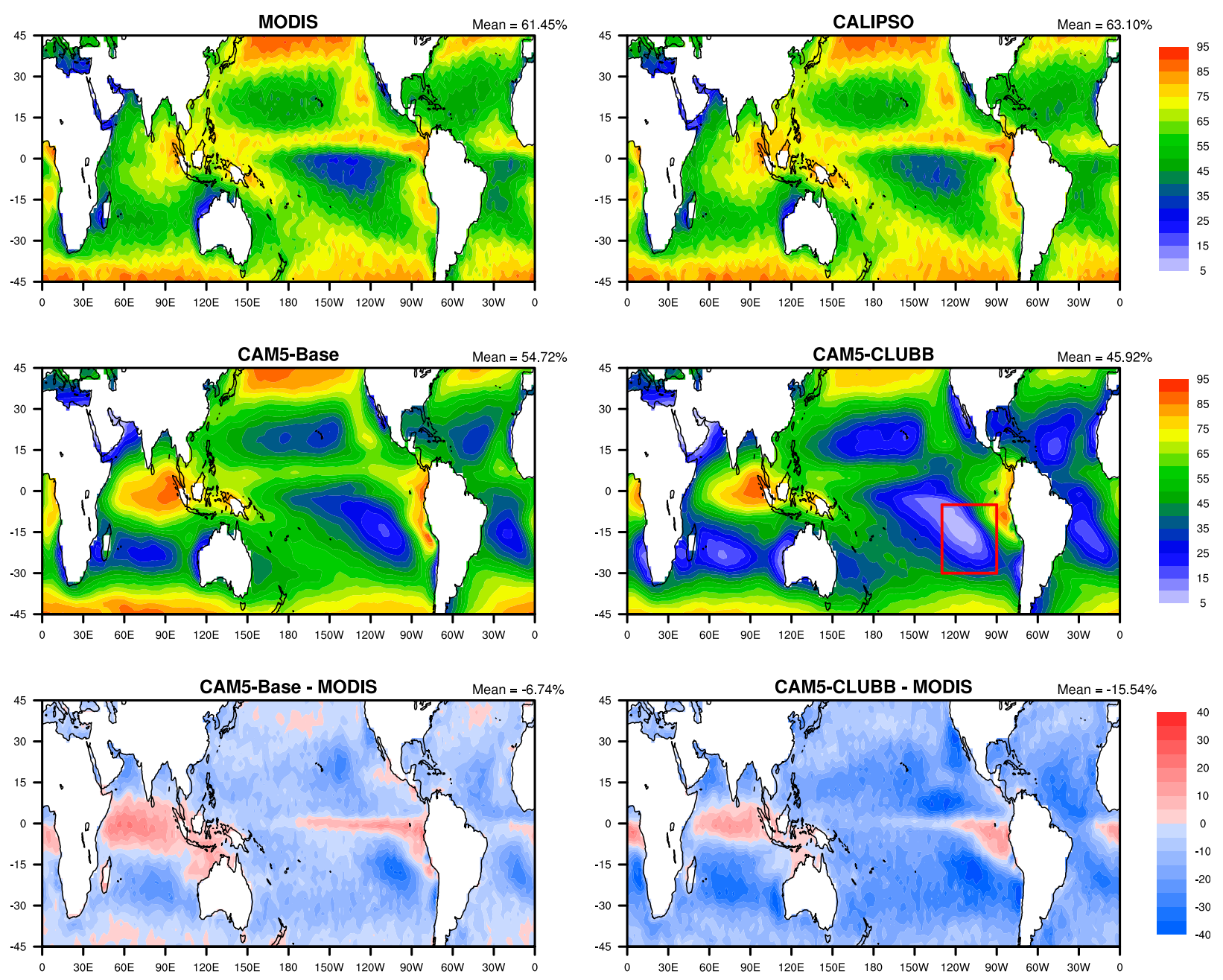

FIG. 5. Annual mean total cloud fraction (\%) in the (top left) MODIS and (top right) CALIPSO observations, (middle left) CAM5Base MODIS simulator, and (middle right) CAM5-CLUBB MODIS simulator. Difference in total cloud fraction (\%) between the two simulations and observations: (bottom left) CAM5-Base - MODIS and (bottom right) CAM5-CLUBB - MODIS.

COSP-MODIS simulation. As explained in section $2 \mathrm{~b}$, to mimic the detection limitation of MODIS, the COSPMODIS simulator uses a minimum detectable threshold of $\tau_{\min }=0.3$ to remove those subvisible clouds that are undetected by MODIS instruments (Pincus et al. 2012), even though the subvisible clouds with $\tau<0.3$ contribute little to the total cloud fraction as suggested by the small difference between MODIS and CALIPSO observations. Evidently, this removal process has a much stronger impact on CAM5-CLUBB than CAM5-Base. Regional mean cloud fraction only reduces by $6.5 \%$ in the CAM5-Base simulation (i.e., $61.3 \%$ in Fig. 1 and $54.7 \%$ in Fig. 5). In contrast, COSP-MODIS simulator removes more than $13 \%$ of cloud fraction from the CAM5-CLUBB simulation (i.e., 58.9\% in Fig. 1 and $45.9 \%$ in Fig. 5). As a result, the COSP-MODIS cloud fraction in CAM5-CLUBB (45.9\%) is significantly lower than in the MODIS observation (61.5\%), and more strikingly even lower than that in CAM5-Base (54.7\%). Accompanying the degradation of cloud fraction simulation is a larger bias in cloud radiative forcing simulation. Figure 6 compares annual-mean SWCF at the top of atmosphere simulated by CAM5-Base and CAM5CLUBB with CERES satellite retrievals. In terms of domain-averaged SWCF, CAM5-CLUBB agrees better with the CERES observations than CAM5-Base. However, in the regions where COSP-MODIS total cloud fraction from CAM5-CLUBB is significantly smaller than MODIS observations (e.g., red box region in SE Pacific), the SWCF in CAM5-CLUBB is also significantly weaker than CERES. This is consistent with the results from other model assessments (Bogenschutz et al. 2013; Zheng et al. 2016), which suggest that CAM5-Base simulates stronger SWCF by producing 

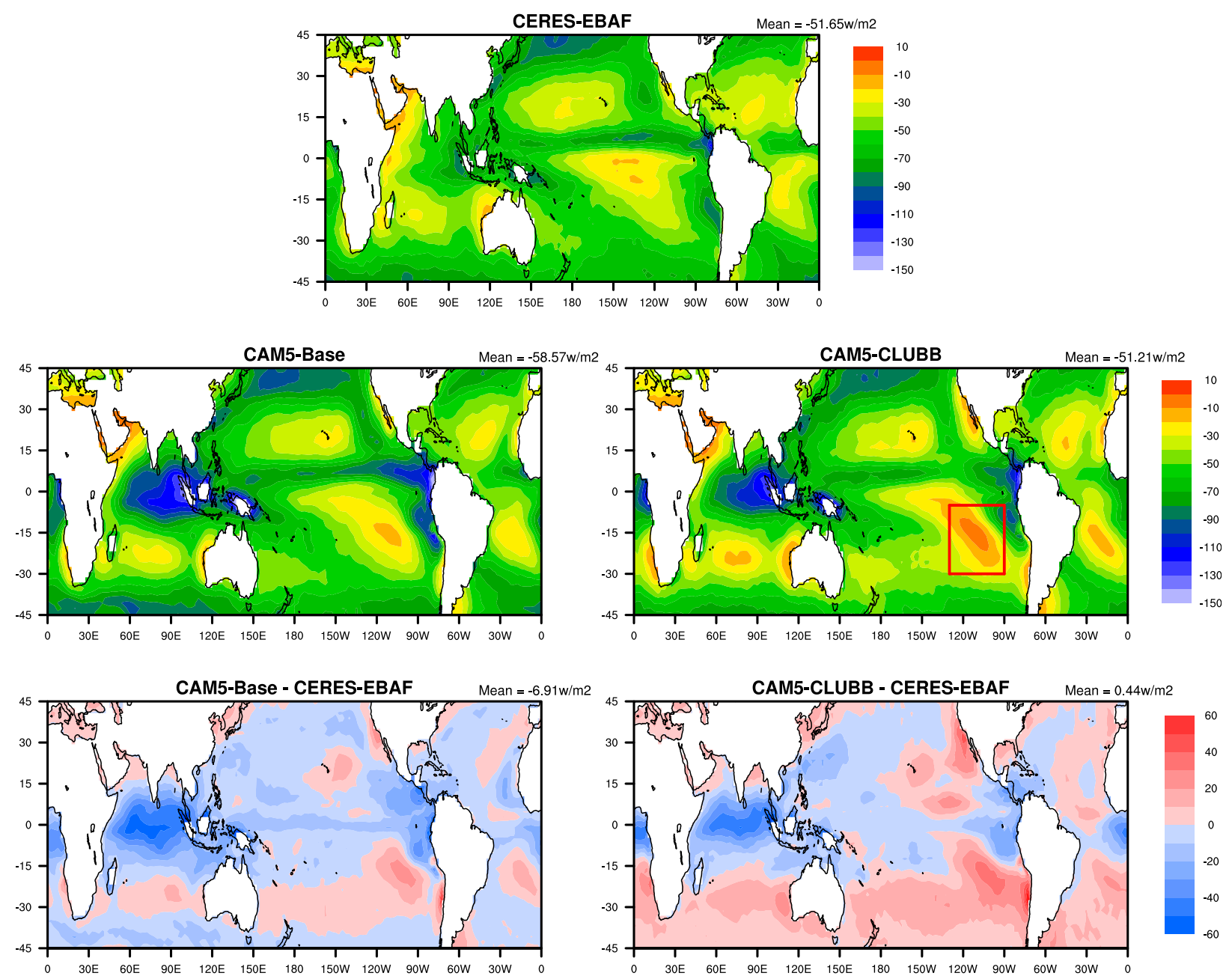

FIG. 6. Annual mean SWCF $\left(\mathrm{W} \mathrm{m}^{-2}\right)$ in the (top) CERES-EBAF observation, (middle left) CAM5-Base, and (middle right) CAM5CLUBB. Difference in SWCF $\left(\mathrm{W} \mathrm{m}^{-2}\right.$ ) between the two simulations and observation: (bottom left) CAM5-Base - CERES and (bottom right) CAM5-CLUBB - CERES.

excessive in-cloud water and the removal of excessive in-cloud water in CAM5-CLUBB degrades SWCF (also seen in Fig. 3).

A comparison between Fig. 5 and Fig. 1 reveals that the STCT regions suffer the most from the cloud reduction after the COSP-MODIS simulator is turned on. To better understand this issue, we selected the red box region in Figs. 5 and 6 where CAM5-CLUBB has significantly smaller cloud fraction and weaker SWCF for a simple sensitivity study. First, we set the minimum detectable threshold of $\tau$ in COSP-MODIS simulator to a near-zero value. Based on the COSP subcolumn outputs, we derived the PDF of cloud fraction as a function of visible cloud optical thickness for the selected region. The results are shown in Fig. 7a. The corresponding cumulative probability functions are shown in Fig. $7 b$. Note that the cumulative probability function of each dataset is normalized to its domain-averaged cloud fraction, instead of unity. For reference, we also plot the results derived from the MODIS product. As shown in Fig. 7a, both CAM5-Base and CAM5-CLUBB simulate a bimodal distribution of cloud optical thickness in the selected region. One peak is around $\tau=4$, and its shape compares reasonably well with MODIS observations. The second peak is the around $\tau=0.02$. If the COSP-MODIS simulator is turned off, this second peak contributes significantly to the total cloud fraction, especially in CAM5-CLUBB. This explains why in Fig. 1 CAM5-CLUBB has a larger cloud fraction than CAM5-Base. However, when the COSP-MODIS simulator is turned on, the second peak around $\tau=0.02$ is removed by the $\tau_{\min }=0.3$ detection threshold (shaded gray region), which explains why in Fig. 5 CAM5CLUBB cloud fraction becomes significantly smaller. 

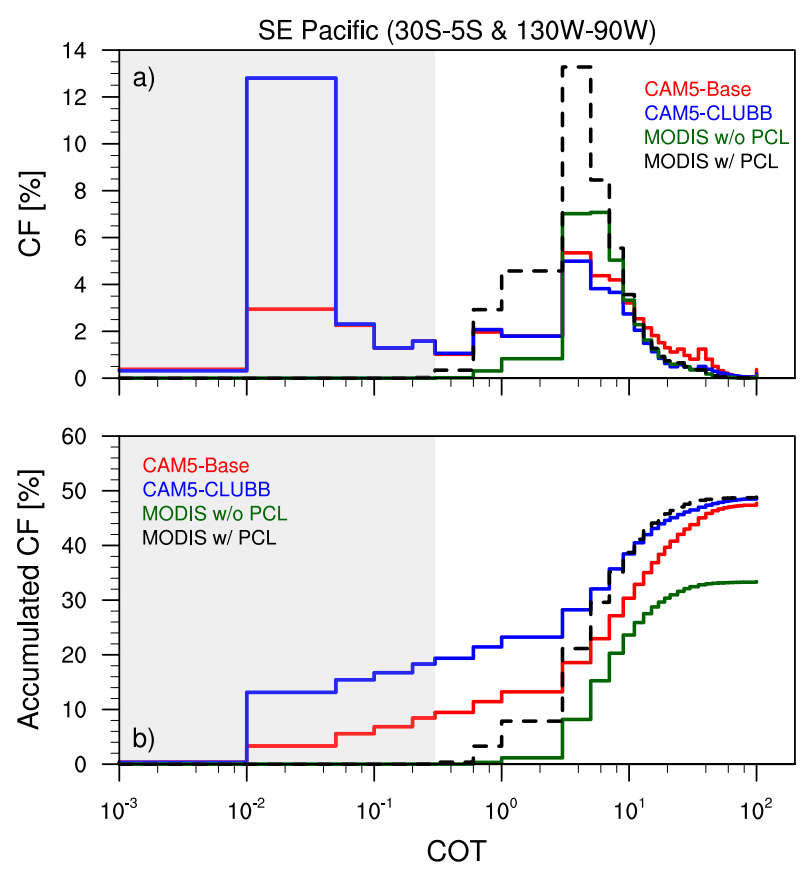

FIG. 7. (a) PDF (\%) of cloud fraction and (b) the corresponding cumulative PDF (\%) as a function of COT in the MODIS observations (green lines for MODIS clouds with retrievals from the PCL pixels excluded; black lines for MODIS with retrievals from PCL pixels included), CAM5-Base MODIS simulator (red lines) and CAM5-CLUBB MODIS simulator (blue lines) over the southeastern Pacific Ocean.

The peak around $\tau=0.02$ in Fig. 8 is the result of those "undetectable clouds" as shown in Fig. 4 (i.e., grid cells with significantly large cloud fraction and near-zero cloud water). This problem is especially severe in CAM5-CLUBB. For the selected region, these undetectable clouds account for about $20 \%$ out of $50 \%$ total cloud fraction in CAM5-CLUBB. Because these undetectable clouds are optically thin, they contribute little to the SWCF, which explains why the SWCF in CAM5-CLUBB is too weak in Fig. 6. On the other hand, it should be noted that in the $\tau>0.3$ region (especially for $\tau>10$ ) the PDF of cloud optical thickness (COT) in CAM5-CLUBB compares arguably better with the MODIS observations than that in CAM5-Base. CAM5-Base simulates too many very bright clouds in the selected region, while the shape of CAM5-CLUBB is aligned well with the MODIS observations.

To further investigate the reasons for the SWCF deficiency in CAM5-CLUBB and detect other problems, in the rest of this section we will focus on the comparison of cloud properties from the two simulations with satellite observations. The annual mean liquid cloud optical thickness $\tau_{\iota}$ from the CAM5-Base and CAM5CLUBB through COSP-MODIS simulator are compared with the MODIS observation in Fig. 8. Note that the $\tau_{\min }=0.3$ detection threshold is turned on in this figure. Compared with the observation, both simulations generate significantly larger $\tau_{\iota}$, especially so in CAM5-Base. This overestimation of the brightness of MBL clouds, together with the low cloud fraction deficiency problem in Fig. 5, indicates that the reasonable SWCF simulation in the MBL cloud regions in CAM5Base is actually a result of error cancellation (i.e., too few, too bright). The $\tau_{\iota}$ simulation in CAM5-CLUBB agrees slightly better with MODIS especially in STCT regions. However, because there are not enough such clouds in CAM5-CLUBB, the SWCF in CAM5CLUBB is too weak in comparison with CERES observation in Fig. 6. Another interesting feature of Fig. 8 is that liquid cloud over the East China Sea is too bright in both simulations compared to MODIS. This issue would be a follow-up study and is beyond the scope of this current study.

Now we turn our attention to the microphysics of MBL clouds. Specifically, we examine the cloud effective radius of liquid phase clouds $r_{e \iota}$ from the COSPMODIS simulator in both simulations in comparison with the MODIS observations. In CAM5-Base, the microphysics of stratiform clouds is handled by the two-moment (i.e., water content and number concentration) MG scheme, which incorporates a variety of microphysical processes such as condensation, autoconversion, and accretion. The $r_{e l}$ is diagnosed from the water content and number concentration under the assumption that the cloud droplets follow the gamma size distribution. In CAM5-Base, a fixed gamma function is assumed for the subgrid cloud water variation for all stratiform clouds. As aforementioned, the UWSC scheme is not yet coupled with the MG scheme in CAM5-Base, and it simply assumes a constant $9 \mu \mathrm{m}$ for $r_{e l}$. The CAM5-Base radiation scheme computes one single cloud fraction and in-cloud LWC/IWC in each layer by combining deep and shallow $\mathrm{Cu}$ and stratus cloud properties through a simple cloud area weighting.

For liquid stratiform clouds, the optical properties, such as $\tau_{\iota}$ and spectral single-scattering albedo, are diagnosed from in-cloud LWC and microphysics from the MG scheme. CAM5-CLUBB also used the MG scheme for cloud microphysics. One major difference between CAM5-CLUBB and CAM5-Base is that both stratiform and shallow convective clouds unified by the CLUBB are coupled with the MG scheme.

Figure 9 compares annual mean $r_{e \iota}$ from the CAM5Base and CAM5-CLUBB through the COSP-MODIS simulator with the MODIS $r_{e \iota}$ product based on the 3.7$\mu \mathrm{m}$ band retrievals. As discussed in several previous studies (Zhang and Platnick 2011; Zhang et al. 2012; Cho et al. 2015; Zhang et al. 2016), the 3.7- $\mu \mathrm{m}$ band 

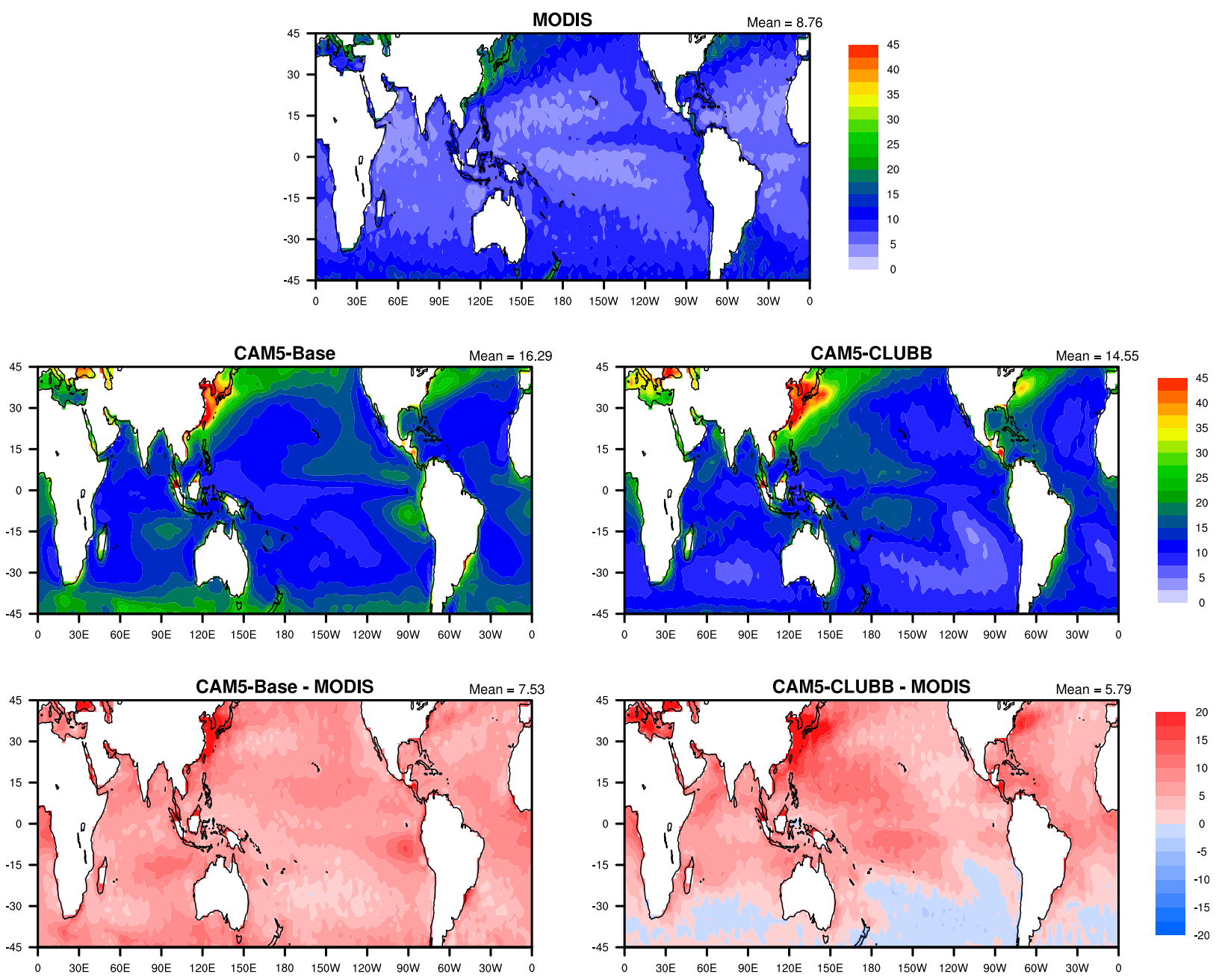

FIG. 8. As in Fig. 5, but for liquid cloud optical thickness.

$r_{e \iota}$ retrieval is more resilient to the 3D effects and retrieval failure than the $2.1-\mu \mathrm{m}$ band retrievals. For these reasons, it is used as the observational reference in this study. Using MODIS 2.1- $\mu \mathrm{m} r_{e \iota}$ retrievals would lead to the same conclusions (Fig. S1 in the supplemental material). A noticeable pattern in the MODIS observations is that $r_{e l}$ is small around $10-12 \mu \mathrm{m}$ over the coastal Sc regions and increases gradually to over $15 \mu \mathrm{m}$ in the openocean $\mathrm{Cu}$ regions. This is reasonable as the coastal Sc clouds are closer to aerosol sources and their growth is limited by a shallower PBL, whereas $\mathrm{Cu}$ clouds in the open-ocean regions are in a relatively clean environment and a deeper PBL that both favor larger droplet size. Compared with the observation, $r_{e}$ is significantly smaller in both simulations, especially in CAM5-Base. In the tropical oceans, $r_{e}$ in CAM5-Base is almost a constant around $9 \mu \mathrm{m}$ with little, if any, spatial variation. This is likely because liquid clouds generated by convective schemes (i.e., UWSC and deep convective) in CAM5-Base simply assume a prescribed value $9 \mu \mathrm{m}$ for $r_{e l}$. It is encouraging to see that CAM5-CLUBB captures some of the spatial variation of $r_{e \iota}$ observed by MODIS. In particular, the increase of $r_{e l}$ from coastal Sc to shallow $\mathrm{Cu}$ in CAM5-CLUBB agrees reasonably well with the MODIS observations. This is likely because both Sc and shallow $\mathrm{Cu}$ clouds are coupled with $\mathrm{MG}$ scheme in CAM5-CLUBB resulting in coherent microphysics in these clouds. However, the increasing trend of $r_{e \iota}$ in CAM5-CLUBB stops where the deep-convective clouds occur more frequently (e.g., western Pacific).

The characteristics of CAM5-Base and CAM5CLUBB for MBL cloud simulations can be summarized using Fig. 10, which shows the meridional mean total cloud fraction, SWCF, liquid cloud fraction $r_{e}$, and $\tau_{\iota}$ from two simulations and observations over three STCT regions. It is clearly seen that the model performances in three regions are consistently similar, implying that the model biases are systematic. Both simulations produce 

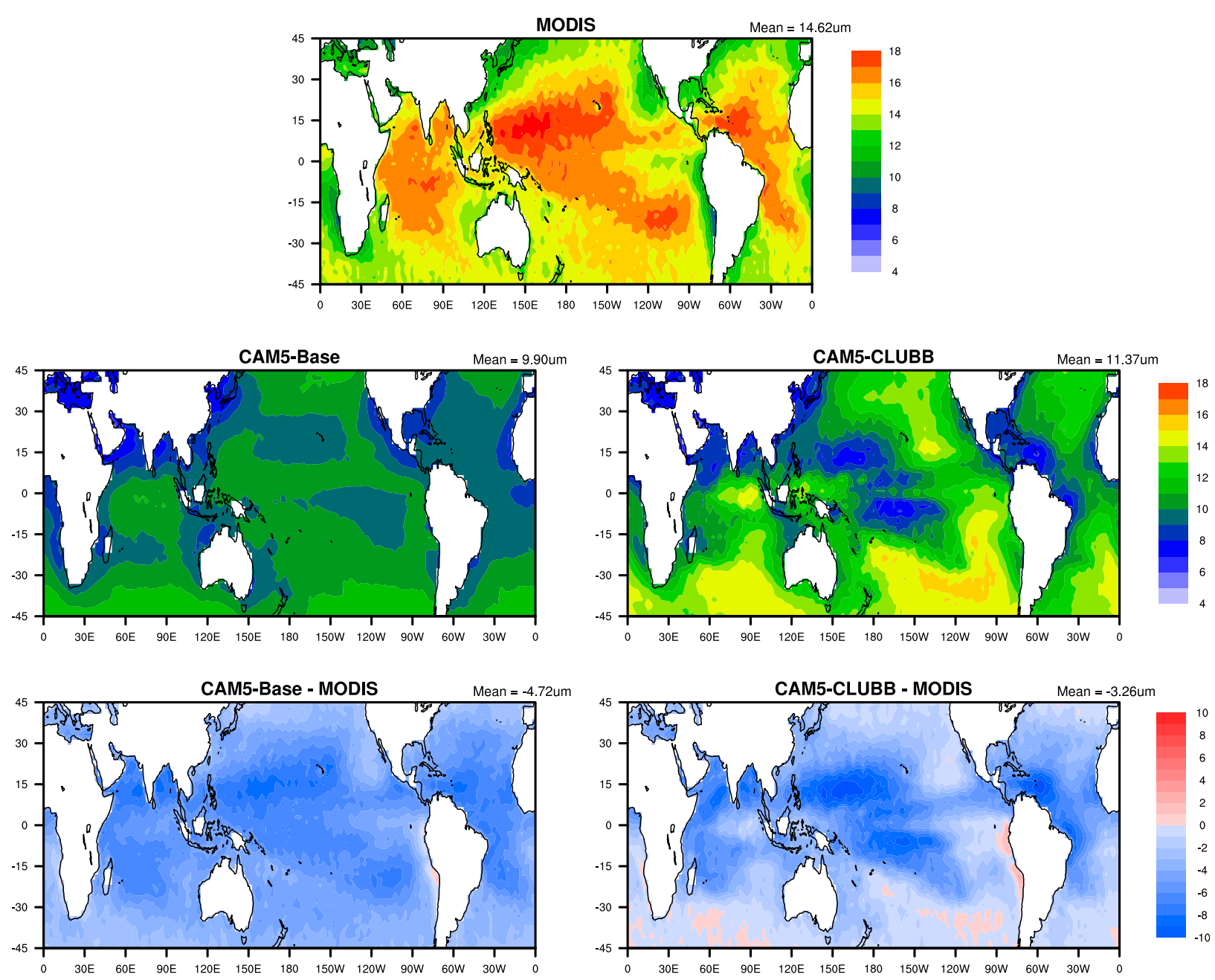

FIG. 9. As in Fig. 5, but for liquid cloud effective radius $(\mu \mathrm{m})$.

smaller total cloud fraction and liquid cloud fraction than the MODIS observations, but CAM5-Base produces much larger $\tau_{\iota}$, and as a result, its SWCF is close to the observation; meanwhile, $\tau_{\iota}$ from CAM5--CLUBB is closer to the observation and thereby its underestimation of cloud fraction leads to a much weaker SWCF than the observation. In addition, there are three points to be emphasized again: 1) From the CAM-Base standard cloud fraction diagnosis (i.e., model direct output), total cloud fraction from CAM5-CLUBB is larger than that from CAM5-Base and much closer to the observations. However, most clouds in CAM5CLUBB are very thin with an optical thickness less than 0.3 , which is below the detection limit of MODIS; therefore, its cloud fraction from the COSP-MODIS simulator is much smaller than that of CAM5-Base (explained in Fig. 7) and the MODIS observations. 2) Model representation of $r_{e}$ is improved significantly from CAM5-Base to CAM5-CLUBB, especially over regions where the CLUBB scheme is dominantly active. 3) The cloud optical thickness in CAM5-Base is too large compared to the observation. The magnitude and spatial pattern of cloud optical thickness in CAM5-CLUBB compare better with the MODIS observations, but there are not enough such clouds to balance the SWCF.

In the above comparisons, MODIS observations include the retrievals from the PCL pixels. The results excluding the PCL pixels are provided in the supplemental material. Apparently, the exclusion of PCL pixels does not remarkably change the MODIS cloud properties except that it significantly increases the MODIS $\tau_{\iota}$ (Figs. S2, $\mathrm{S} 3$, and S4 in the supplemental material), which is expected because the PCL pixels are mostly cloud edges that tend to be optically thin (Cho et al. 2015). Arguments about trade-off between sampling bias and retrieval bias related with the PCL pixels are clearly addressed in the study of Pincus et al. (2012). Here, we present the results from both scenarios to give the readers a more complete 


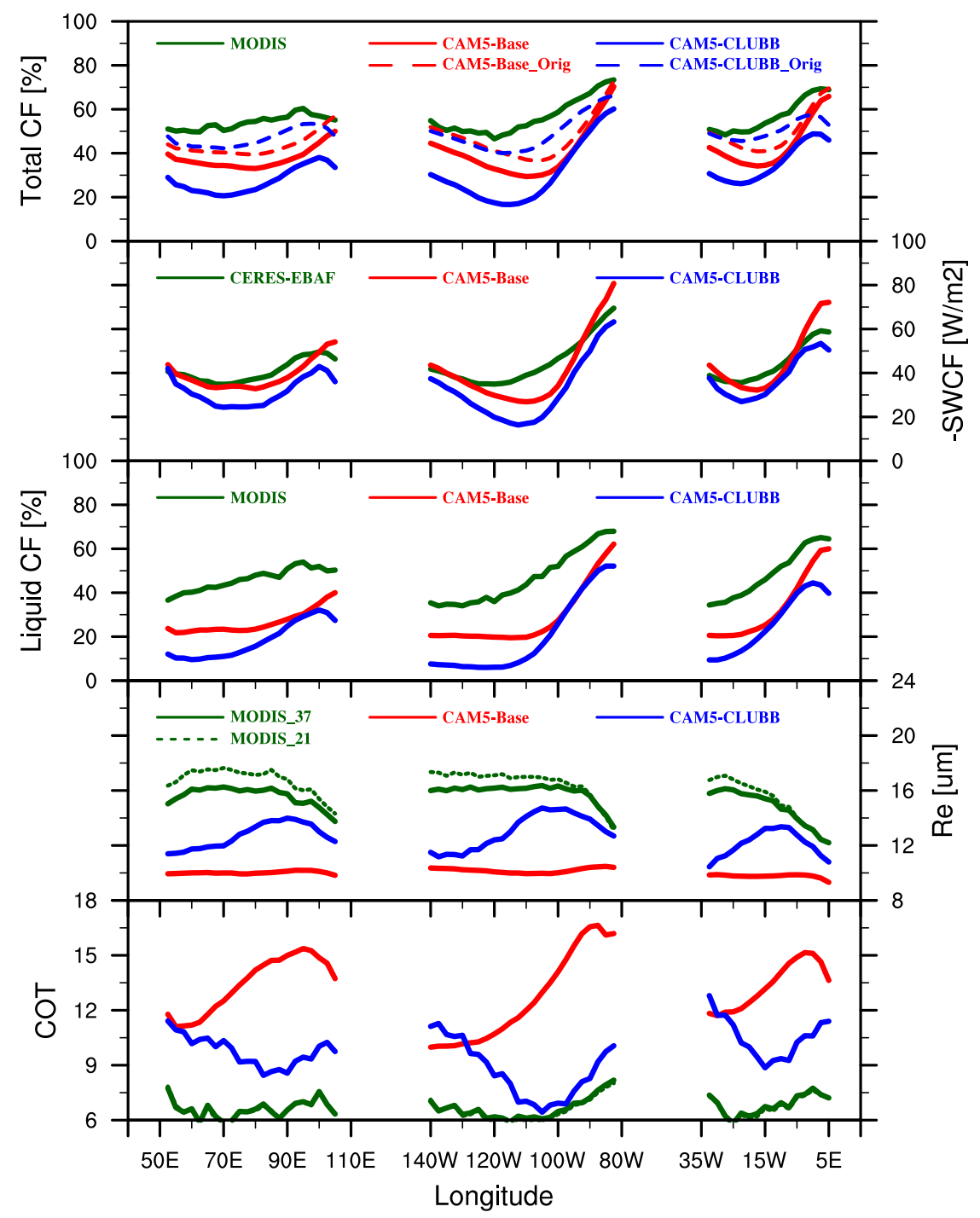

FIG. 10. Meridional mean total cloud fraction, SWCF, liquid cloud fraction, liquid cloud effective radius, and liquid cloud optical thickness over the south Indian, southeastern Pacific, and South Atlantic Oceans in the satellite observations (green lines), CAM5-Base (red lines), and CAM5-CLUBB (blue lines).

picture. Fortunately, whether or not to include PCL pixels does not change our conclusions. Even after the exclusion of PCL pixels, MODIS $\tau_{\iota}$ is still significantly smaller than that in the CAM5-Base run and compares better with the CAM5-CLUBB simulation.

\section{Evaluation of warm rain simulation}

Many previous studies have shown that the warm rain process plays an important role in determining the macro- and microphysical properties of MBL clouds, in particular, the cloud water budget (Stevens et al. 2005; Wood 2005; Comstock et al. 2005). The comparisons with MODIS and CERES observations in the previous section have exposed some potential issues in the model. For example, we found that CAM5-CLUBB often simulates "undetectable" MBL clouds. A potential cause of this issue might be rooted in the simulation of warm rain process in the model. Motivated by these considerations, in this section we compare the COSP-CloudSat simulations based on modeled cloud fields (i.e., CAM5-Base and CAM5-CLUBB) with the CloudSat products, with special attention on the warm rain process.

First, we compare the contoured frequency by altitude diagram (CFAD) of tropical and subtropical clouds derived based on CAM5-Base and CAM5CLUBB COSP simulations with that derived from the CloudSat 2B-GEOPROF product in Fig. 11. The 

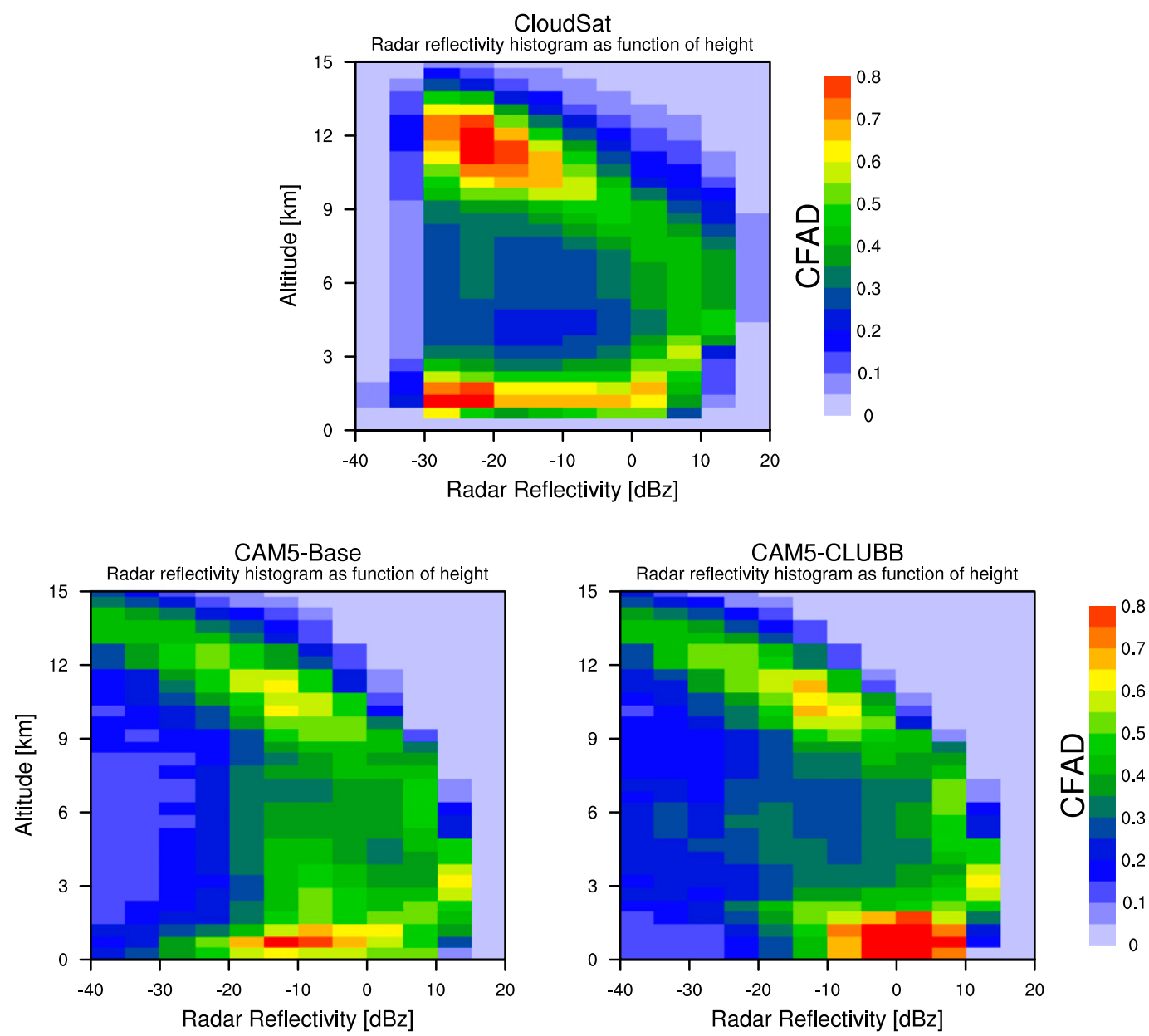

FIG. 11. Tropical averaged radar reflectivity-height histogram in (top) the CloudSat observation and (bottom left) the CAM5-Base and (bottom right) CAM5-CLUBB CloudSat simulators.

CFAD-based CloudSat observations display a typical boomerang-type shape that has been reported in many previous studies Bodas-Salcedo et al. 2011; Zhang et al. 2010; Marchand et al. 2009). Focusing on the low clouds below $3 \mathrm{~km}$, we observe a rather broad distribution of radar reflectivity with a maximum occurrence frequency from around -30 to $-20 \mathrm{~dB} Z$ followed by a long tail extending to about $10 \mathrm{~dB} Z$. As pointed out in previous studies, the peak from around -30 to $-20 \mathrm{~dB} Z$ is due to nonprecipitating MBL clouds, and the precipitating clouds with increasing rain rate give rise to the long tail. The CFAD based on two model simulations exhibits some characteristics similar to the CloudSat observations, but also many noticeable differences. In particular, we note that the two simulations both produce a much narrower range of radar reflectivity for low clouds, with occurrence frequency clustered mostly around -10 and $0 \mathrm{dBZ}$ in CAM5-Base and CAM5CLUBB, respectively.
Several previous studies suggested that when the maximum CloudSat radar reflectivity $\mathrm{dB} Z_{\text {max }}$ observed exceeds $-15 \mathrm{db} Z$ there are likely to be significant amounts of drizzle drops developed in MBL clouds. Therefore, $\mathrm{dB} Z_{\max }>-15 \mathrm{~dB} Z$ is often used in the literature to distinguish precipitating from nonprecipitating MBL clouds (Kubar et al. 2009; Lebsock and Su 2014; Haynes et al. 2009). Using this threshold, we derived the probability of precipitation (POP) in MBL clouds based on the collocated CloudSat and MODIS observations as shown in Fig. 12. The POP for a given grid box is defined as the fraction of liquid-phase cloud identified by MODIS with the $\mathrm{dB} Z_{\max }>-15 \mathrm{~dB} Z$ according to the collocated CloudSat observations with respect to the total population liquid-phase clouds in the grid. We note that CloudSat observations can miss a significant fraction of MBL clouds that are observed by MODIS, because these clouds are either too thin and therefore their radar reflectivity is too weak to be 

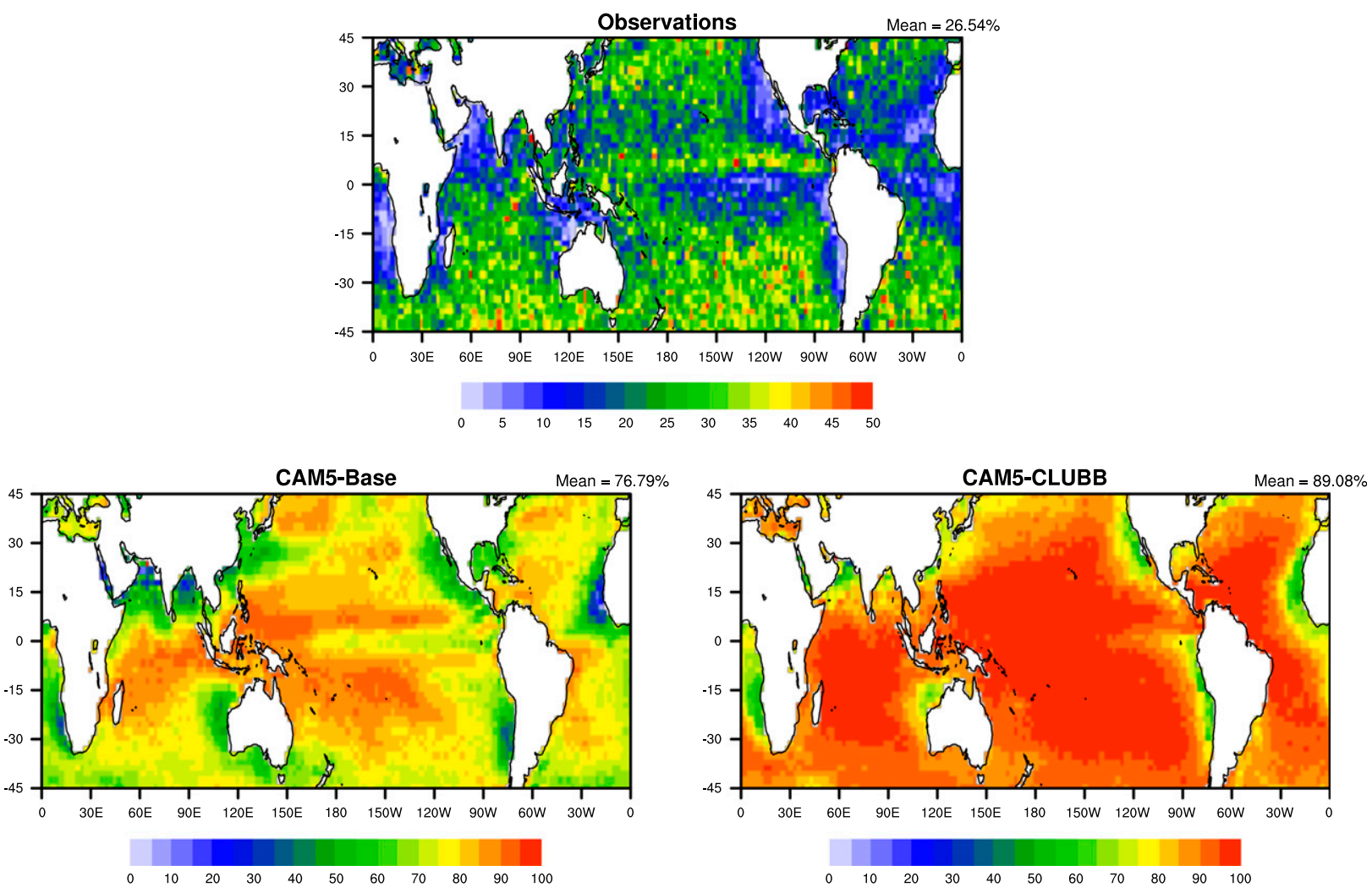

FIG. 12. Fraction (\%) of precipitating liquid clouds in (top) the satellite observations and (bottom left) the CAM5-Base and (bottom right) CAM5-CLUBB satellite simulators.

detected by CloudSat, or they are too low and therefore suffer the surface clutter issue (Marchand et al. 2008). Because these clouds are thin and/or low, they are assumed to be nonprecipitating in this study. Observations in Fig. 12 suggest that roughly a quarter of MBL clouds observed by MODIS in the tropical and subtropical region are likely precipitating, with a domain-averaged POP around $26 \%$. The POP has a distinct pattern: smaller $(\sim 10 \%)$ in the coastal Sc regions and increasing to $\sim 30 \%$ in the $\mathrm{Cu}$ cloud regions. An earlier study by Kubar et al. (2009) also noted such pattern (see their Fig. 3) and suggested that it is a result of combined effect of increasing LWP and decreasing cloud droplet number concentration from $\mathrm{Sc}$ regime to $\mathrm{Cu}$ regime.

Using the subcolumns from the COSP simulator, we can derive the POP based on model simulations in the way consistent with satellite observations. Each subcolumn generated by the COSP simulator has associated MODIS and CloudSat simulations. In the same way as we define POP for observations, we define the POP for model simulations as the ratio of subcolumns that have COSP-CloudSat simulated $\mathrm{dB} Z_{\max }>-15 \mathrm{dBZ}$ with respect to the total number of liquid-phase clouds identified by COSP-MODIS. When comparing with the observations in Fig. 12, we found that the POP based on COSP simulations in both CAM5-Base and CAM5CLUBB is substantially higher, with domain-averaged POP close to $80 \%$ and $90 \%$, respectively. Although striking, these results can be expected from CFAD results in Fig. 11 (i.e., both models have a narrow dBZ distribution with the maximum occurrence frequency well above $-15 \mathrm{~dB} Z$ ). Despite the large difference with observations in magnitude, both models simulate the general increase of $\mathrm{POP}$ from $\mathrm{Sc}$ regime to $\mathrm{Cu}$ regime. It is also noticeable that the difference in POP between CAM5-Base and CAM5-CLUBB is substantial over the cumulus-dominated regimes.

The dramatic difference between observed and modeled POP as shown in Fig. 12 indicates that the drizzle is triggered too frequently in the model. The toofrequent rain production in GCMs is a well-known issue reported by many previous studies (e.g., Zhang et al. 2010; Bodas-Salcedo et al. 2011; Franklin et al. 2013; Suzuki et al. 2015). Currently, the microphysical processes that trigger the initiation of drizzle drops in MBL are still not well understood. In the models, even the state-of-the-art microphysics scheme like MG08 still simulates the warm rain process on the basis of 

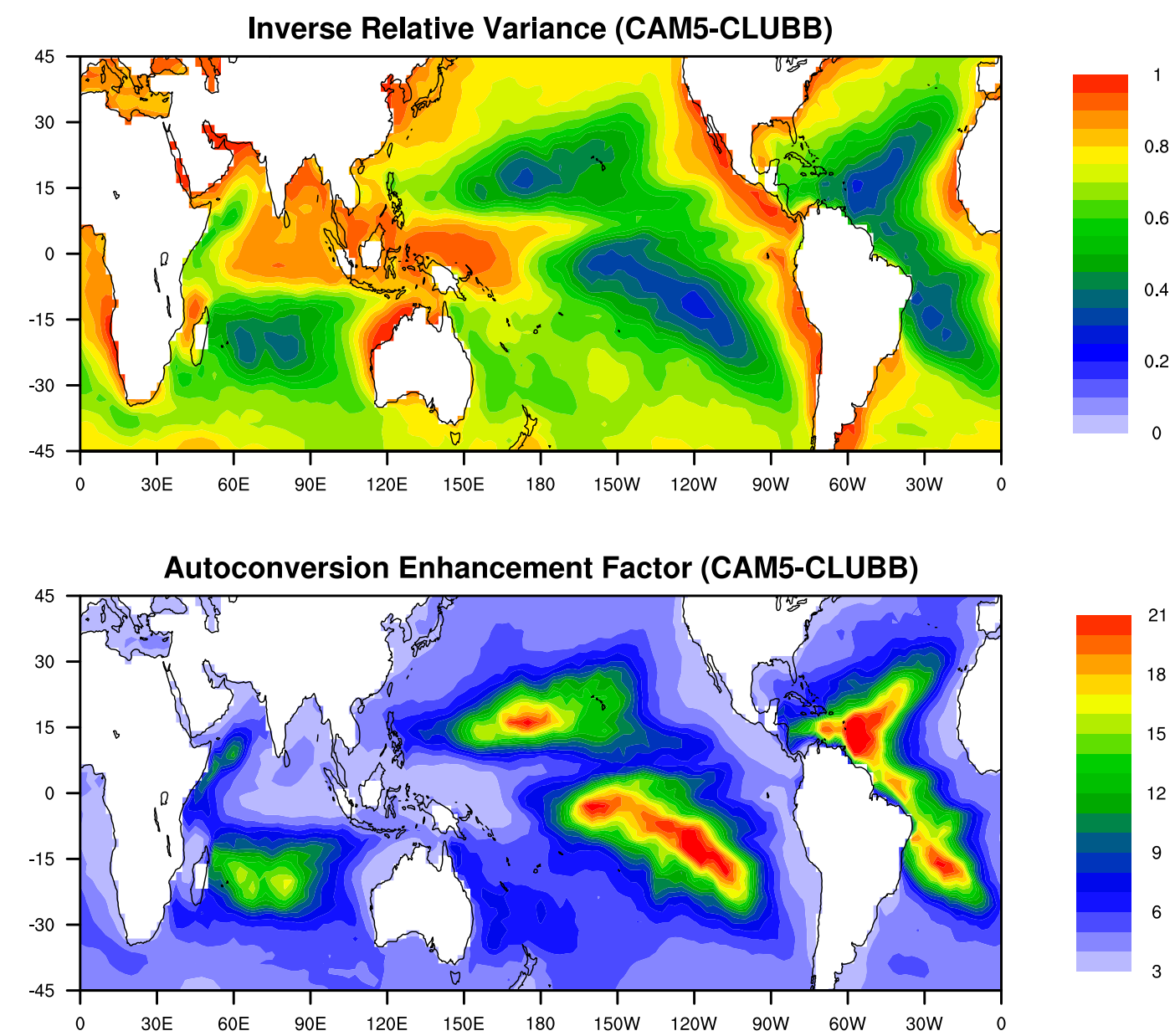

FIG. 13. (top) Annual mean column-averaged inverse relative variance and (bottom) autoconversion enhancement factor weighted by in-cloud water mixing ratio in CAM5-CLUBB.

simplified autoconversion and accretion parameterization scheme (Khairoutdinov and Kogan 2000). Because the warm rain processes, autoconversion in particular, are nonlinear functions of cloud water content, they depend on not only grid-mean cloud water but also the subgrid cloud water distribution. As such, when calculating the grid-mean autoconversion rate, the MG08 scheme has to use a so-called enhancement factor to take into account the difference between the result diagnosed from the mean value of in-cloud water and that diagnosed from the full subgrid cloud water distribution. The value of the enhancement factor is determined by the shape of the subgrid cloud water distribution. As explained in section 2a, in CAM5-Base, the MG08 scheme simply assumes a gamma distribution with a fixed inverse relative variance $(\nu=1)$ for subgrid cloud water distribution, which leads to a constant enhancement factor of 3.22 for the autoconversion process at each grid point. Note that this is significantly larger than the global median and mean values (1.86 and 2.29, respectively) reported in Lebsock et al. (2013) that are derived based on MODIS and CloudSat observations. In CAM5-CLUBB, the MG08 uses the subgrid cloud water variance from CLUBB to determine the inverse relative variance $\nu$ and the corresponding enhancement factor (Guo et al. 2014). Figure 13 shows the vertically averaged inverse relative variance $\nu$ and the corresponding enhancement factor in CAM5-CLUBB. Note that the vertical average is weighted by the in-cloud water mixing ratio. Evidently, the $\nu$ value is much smaller than unity in the CAM5-CLUBB, leading to a much larger enhancement factor than the observations and that used in the CAM5-Base. Indeed, in regions where the CAM5-CLUBB suffers most from the cloud fraction deficit, weaker SWCF, and excessive drizzling, the enhancement factor can be as large as 20. Figure 13 suggests that the excessive drizzle problem in CAM5CLUBB might be caused by the unrealistically large enhancement factor in the simulation of warm rain process. The excessive drizzle in turn rains out the 
in-cloud water, leading to large amounts of "undetectable" thin clouds and weak SWCF. It is important to point out here that, the unrealistic enhancement factor should not be interpreted simply as the problem of CLUBB. As mentioned in section 2a, CLUBB assumes a double-Gaussian distribution for subgrid cloud water while the MG08 scheme assumes a gamma distribution. Recently, Larson and Schanen (2013) have proposed a new modeling framework based on the subgrid importance of the Latin Hypercube sampler to resolve this fundamental discrepancy and enable a better coupling between CLUBB and microphysics schemes like MG08.

Finally, we need to point out another factor that could also contribute to the narrow distribution of MBL cloud radar reflectivity and the unrealistic high POP in the model. As explained in section $2 b$, the COSP uses the socalled subcolumn generator to distribute the grid-mean cloud and precipitation into subcolumns. As described in Zhang et al. (2010), the current scheme used in this process is very simple. In particular, it accounts only for the subgrid variability of the types of hydrometeors and ignores the variability of mass and microphysics within each hydrometeor type. Such an oversimplified scheme might be an important reason why the distribution of MBL cloud radar reflectivity is too narrow in the model in comparison with CloudSat observations. In this regard, an improved subcolumn generator needs to be developed in future research for COSP to account for the subgrid variances of cloud and/or hydrometeor mass and microphysics.

\section{Summary and outlook}

This study presents a comprehensive evaluation of the simulated MBL cloud properties in two CAM runs: CAM5-Base and CAM5-CLUBB. In the comparisons of direct model outputs, we find that the CAM5CLUBB run produces more MBL clouds (Fig. 1), a smoother transition from $\mathrm{Sc}$ to $\mathrm{Cu}$ (Fig. 2), and a tighter correlation between in-cloud water and cloud fraction (Fig. 3) than the CAM5-Base run. These changes by CLUBB have also been reported by several previous evaluation studies (Bogenschutz et al. 2013; Kubar et al. 2015). In the model-to-observation comparison, we find that both simulations largely capture the main features and spatial patterns of the observed MODIS cloud fraction (Fig. 5) and CERES SWCF (Fig. 6). However, the CAM5-CLUBB suffers from a problem that can be best summarized as "undetectable" clouds (i.e., a large cloud fraction with near-zero in-cloud water) (Figs. 4 and 7). Owing to the undetectable cloud problem, the CAM5-CLUBB has a smaller COSP-MODIS cloud fraction and a weaker SWCF than CAM5-Base and the observations in the descending regions. When evaluating cloud microphysics, we note an encouraging improvement of CAM5-CLUBB. It is able to simulate, although only qualitatively, the cloud droplet size increase from coastal $\mathrm{Sc}$ to open-ocean $\mathrm{Cu}$ as observed by MODIS (Fig. 9). In CAM5-Base, the cloud droplet size almost remains a constant. This improvement is a result of better coupling between shallow convective clouds and the MG08 cloud microphysics scheme in CAM5CLUBB. Finally, we compare radar reflectivity simulations from COSP based on the two model simulations with CloudSat observations. We find that in comparison with observations the histogram of the radar reflectivity from COSP is too narrow without a distinct separation between cloud mode and drizzle mode (Fig. 11). Moreover, the POPs in both simulations are much higher than that derived based on collocated CloudSat and MODIS observations (Fig. 12). This excessive drizzle problem is especially severe in the CAM5CLUBB, which seems to be caused by the use of unrealistically large autoconversion enhancement factor in the simulation of warm rain process in the model (Fig. 13). In CAM5-CLUBB, the strongly enhanced autoconversion from cloud water to rainwater makes the MBL clouds precipitate too excessively, resulting in too many undetectable thin clouds. The undetectable cloud problem in CAM5-CLUBB exposed here seems consistent with a recent study by Zheng et al. (2016). They found that CLUBB improves the simulation of cloud base height, the height of the major cloud layer, and the daily cloud cover variability. It also better simulates the relationship of cloud fraction to LWP than CAM5-Base. However, they noted that CLUBB does not improve the simulation of the surface shortwave cloud radiative effect [see Fig. 14 in Zheng et al. (2016)].

Overall, the results from this study indicate that there is still significant space for improvement of CAM5CLUBB. In particular, substantial efforts are needed to improve the coupling between CLUBB and other components of the model. The subgrid cloud water PDFs from the CLUBB also need observation-based evaluation. Finally, in the comparisons with CloudSat observations, we find that there still exists a significant gap between model and observation even if the COSP simulator is used. To close this gap, a more comprehensive subcolumn generator that is able to account for subgrid variation of hydrometeor mass and microphysics is needed for the COSP simulator.

Acknowledgments. This research is supported by U.S. Department of Energy (DOE), Office of Science, Biological and Environmental Research, Regional and Global Climate Modeling Program (Grant DE-SC0014641) and 
the Minister of Science and Technology of China (2017YFA0604001). The Pacific Northwest National Laboratory is operated for the DOE by Battelle Memorial Institute under Contract DE-AC05-76RLO 1830. The computations in this study were performed at the UMBC High Performance Computing Facility (HPCF). The facility is supported by the U.S. National Science Foundation through the MRI program (Grants CNS-0821258 and CNS-1228778) and the SCREMS program (Grant DMS-0821311), with substantial support from UMBC. MODIS cloud products used in this study are downloaded from NASA Level-1 and Atmosphere Archive and Distribution System (https://ladsweb.modaps.eosdis.nasa.gov/). CloudSat products are provided by CloudSat Data Processing Center (http://www.cloudsat.cira.colostate.edu/). CERES products are provided by NASA Atmospheric Science Data Center (https://eosweb.larc.nasa.gov). We thank Editor Dr. Stephen Klein and three anonymous reviewers for their insightful and constructive comments.

\section{REFERENCES}

Ackerman, A. S., K. Strabala, W. Menzel, R. Frey, C. Moeller, and L. Gumley, 1998: Discriminating clear sky from clouds with MODIS. J. Geophys. Res., 103, 32 141-32 157, https://doi.org/ 10.1029/1998JD200032.

— O. B. Toon, J. P. Taylor, D. W. Johnson, P. V. Hobbs, and R. J. Ferek, 2000: Effects of aerosols on cloud albedo: Evaluation of Twomey's parameterization of cloud susceptibility using measurements of ship tracks. J. Atmos. Sci., 57, 2684-2695, https://doi.org/10.1175/1520-0469(2000)057<2684: EOAOCA $>2.0 . \mathrm{CO} ; 2$.

Bodas-Salcedo, A., and Coauthors, 2011: COSP: Satellite simulation software for model assessment. Bull. Amer. Meteor. Soc., 92, 1023-1043, https://doi.org/10.1175/2011BAMS2856.1.

Bogenschutz, P. A., A. Gettelman, H. Morrison, V. E. Larson, D. P. Schanen, N. R. Meyer, and C. Craig, 2012: Unified parameterization of the planetary boundary layer and shallow convection with a higher-order turbulence closure in the Community Atmosphere Model. Geosci. Model Dev., 5, 14071423, https://doi.org/10.5194/gmd-5-1407-2012.

,,,---- C. Craig, and D. P. Schanen, 2013: Higherorder turbulence closure and its impact on climate simulations in the Community Atmosphere Model. J. Climate, 26, 96559676, https://doi.org/10.1175/JCLI-D-13-00075.1.

Bretherton, C. S., and S. Park, 2009: A new moist turbulence parameterization in the Community Atmosphere Model. J. Climate, 22, 3422-3448, https://doi.org/10.1175/ 2008JCLI2556.1.

Cho, H. M., P. Yang, G. W. Kattawar, S. L. Nasiri, Y. Hu, P. Minnis, C. Trepte, and D. Winker, 2008: Depolarization ratio and attenuated backscatter for nine cloud types: Analyses based on collocated CALIPSO lidar and MODIS measurements. Opt. Express, 16, 3931-3948, https://doi.org/ 10.1364/OE.16.003931.

, and Coauthors, 2015: Frequency and causes of failed MODIS cloud property retrievals for liquid phase clouds over global oceans. J. Geophys. Res. Atmos., 120, 4132-4154, https://doi.org/10.1002/2015JD023161.
Coakley, J. A., Jr., and C. D. Walsh, 2002: Limits to the aerosol indirect radiative effect derived from observations of ship tracks. J. Atmos. Sci., 59, 668-680, https://doi.org/10.1175/ 1520-0469(2002)059<0668:LTTAIR>2.0.CO;2.

Comstock, K. K., C. S. Bretherton, and S. E. Yuter, 2005: Mesoscale variability and drizzle in southeast Pacific stratocumulus. J. Atmos. Sci., 62, 3792-3807, https://doi.org/10.1175/ JAS3567.1.

Doelling, D. R., and Coauthors, 2013: Geostationary enhanced temporal interpolation for CERES flux products. J. Atmos. Oceanic Technol., 30, 1072-1090, https://doi.org/10.1175/ JTECH-D-12-00136.1.

Dolinar, E., X. Dong, B. Xi, J. Jiang, and H. Su, 2015: Evaluation of CMIP5 simulated clouds and TOA radiation budgets using NASA satellite observations. Climate Dyn., 44, 2229-2247, https://doi.org/10.1007/s00382-014-2158-9.

Franklin, C. N., Z. Sun, D. Bi, M. Dix, H. Yan, and A. BodasSalcedo, 2013: Evaluation of clouds in ACCESS using the satellite simulator package COSP: Regime-sorted tropical cloud properties. J. Geophys. Res. Atmos., 118, 6663-6679, https://doi.org/10.1002/jgrd.50496.

Gettelman, A., and Coauthors, 2010: Global simulations of ice nucleation and ice supersaturation with an improved cloud scheme in the Community Atmosphere Model. J. Geophys. Res., 115, D18216, https://doi.org/ 10.1029/2009JD013797.

Golaz, J.-C., V. E. Larson, and W. R. Cotton, 2002a: A PDFbased model for boundary layer clouds. Part II: Model results. J. Atmos. Sci., 59, 3552-3571, https://doi.org/10.1175/ 1520-0469(2002)059<3552:APBMFB > 2.0.CO;2.

,$- \ldots$, and ——, 2002b: A PDF-based model for boundary layer clouds. Part I: Method and model description. J. Atmos. Sci., 59, 3540-3551, https://doi.org/10.1175/ 1520-0469(2002)059<3540:APBMFB > 2.0.CO;2.

Grosvenor, D. P., and R. Wood, 2014: The effect of solar zenith angle on MODIS cloud optical and microphysical retrievals within marine liquid water clouds. Atmos. Chem. Phys., 14, 7291-7321, https://doi.org/10.5194/acp-14-7291-2014.

Guo, H., J. C. Golaz, L. J. Donner, P. A. Ginoux, and R. S. Hemler, 2014: Multivariate probability density functions with dynamics in the GFDL atmospheric general circulation model: Global tests. J. Climate, 27, 2087-2108, https://doi.org/10.1175/ JCLI-D-13-00347.1.

,,-- B. Wyman, M. Zhao, and P. Ginoux, 2015: CLUBB as a unified cloud parameterization: Opportunities and challenges. Geophys. Res. Lett., 42, 4540-4547, https:// doi.org/10.1002/2015GL063672.

Haynes, J. M., T. S. L'Ecuyer, G. L. Stephens, S. D. Miller, C. Mitrescu, N. B. Wood, and S. Tanelli, 2009: Rainfall retrieval over the ocean with spaceborne W-band radar. J. Geophys. Res., 114, D00A22, https://doi.org/10.1029/ 2008JD009973.

Holz, R. E., S. A. Ackerman, F. W. Nagle, R. Frey, S. Dutcher, R. E. Kuehn, M. A. Vaughan, and B. Baum, 2008: Global Moderate Resolution Imaging Spectroradiometer (MODIS) cloud detection and height evaluation using CALIOP. J. Geophys. Res., 113, D00A19, https://doi.org/10.1029/ 2008JD009837.

Iacono, M. J., J. S. Delamere, E. J. Mlawer, M. W. Shephard, S. A. Clough, and W. D. Collins, 2008: Radiative forcing by longlived greenhouse gases: Calculations with the AER radiative transfer models, J. Geophys. Res., 113, D13103, https://doi.org/ 10.1029/2008JD009944. 
Jiang, J. H., and Coauthors, 2012: Evaluation of cloud and water vapor simulations in CMIP5 climate models using NASA "A-Train" satellite observations. J. Geophys. Res., 117, D14105, https://doi.org/10.1029/2011JD017237.

Kato, S., and A. Marshak, 2009: Solar zenith and viewing geometry dependent errors in satellite retrieved cloud optical thickness: Marine stratocumulus case. J. Geophys. Res., 114, D01202, https://doi.org/10.1029/2008JD010579.

Kay, J. E., and Coauthors, 2012: Exposing global cloud biases in the community atmosphere model (CAM) using satellite observations and their corresponding instrument simulators. J. Climate, 25, 5190-5207, https://doi.org/10.1175/ JCLI-D-11-00469.1.

Khairoutdinov, M., and Y. Kogan, 2000: A new cloud physics parameterization in a large-eddy simulation model of marine stratocumulus. Mon. Wea. Rev., 128, 229-243, https://doi.org/ 10.1175/1520-0493(2000)128<0229:ANCPPI > 2.0.CO;2.

Klein, S. A., and D. Hartmann, 1993: The seasonal cycle of low stratiform clouds. J. Climate, 6, 1587-1606, https://doi.org/ 10.1175/1520-0442(1993)006<1587:TSCOLS >2.0.CO;2.

_- Y. Zhang, M. D. Zelinka, R. Pincus, J. Boyle, and P. J. Gleckler, 2013: Are climate model simulations of clouds improving? An evaluation using the ISCCP simulator. J. Geophys. Res. Atmos., 118, 1329-1342, https://doi.org/ 10.1002/jgrd.50141.

Kubar, T. L., D. L. Hartmann, and R. Wood, 2009: Understanding the importance of microphysics and macrophysics for warm rain in marine low clouds. Part I: Satellite observations. J. Atmos. Sci., 66, 2953-2972, https://doi.org/10.1175/ 2009JAS3071.1.

_ G. L. Stephens, M. Lebsock, V. E. Larson, and P. A. Bogenschutz, 2015: Regional assessments of low clouds against large-scale stability in CAM5 and CAM-CLUBB using MODIS and ERAInterim reanalysis data. J. Climate, 28, 1685-1706, https://doi.org/ 10.1175/JCLI-D-14-00184.1.

Larson, V. E., and D. P. Schanen, 2013: The Subgrid Importance Latin Hypercube Sampler (SILHS): A multivariate subcolumn generator. Geosci. Model Dev., 6, 1813-1829, https:// doi.org/10.5194/gmd-6-1813-2013.

_ J.-C. Golaz, and W. R. Cotton, 2002: Small-scale and mesoscale variability in cloudy boundary layers: Joint probability density functions. J. Atmos. Sci., 59, 3519-3539, https://doi.org/ 10.1175/1520-0469(2002)059<3519:SSAMVI $>2.0 . \mathrm{CO} ; 2$.

Lebsock, M., and H. Su, 2014: Application of active spaceborne remote sensing for understanding biases between passive cloud water path retrievals. J. Geophys. Res. Atmos., 119, 8962-8979, https://doi.org/10.1002/2014JD021568.

_ , H. Morrison, and A. Gettelman, 2013: Microphysical implications of cloud-precipitation covariance derived from satellite remote sensing. J. Geophys. Res. Atmos., 118, 6521-6533, https://doi.org/10.1002/jgrd.50347.

Loeb, N. G., and Coauthors, 2012: Advances in understanding topof-atmosphere radiation variability from satellite observations. Surv. Geophys., 33, 359-385, https://doi.org/10.1007/ s10712-012-9175-1.

Ma, P.-L., and Coauthors, 2013: The role of circulation features on black carbon transport into the Arctic in the Community Atmosphere Model version 5 (CAM5). J. Geophys. Res. Atmos., 118, 4657-4669, https://doi.org/10.1002/jgrd.50411.

, and Coauthors, 2015: How does increasing horizontal resolution in a global climate model improve the simulation of aerosol-cloud interactions? Geophys. Res. Lett., 42, 50585065, https://doi.org/10.1002/2015GL064183.
Marchand, R., G. G. Mace, T. Ackerman, and G. Stephens, 2008: Hydrometeor detection using Cloudsat-An Earth-orbiting 94-GHz cloud radar. J. Atmos. Oceanic Technol., 25, 519-533, https://doi.org/10.1175/2007JTECHA1006.1.

, J. Haynes, G. G. Mace, T. Ackerman, and G. Stephens, 2009: A comparison of simulated cloud radar output from the multiscale modeling framework global climate model with CloudSat cloud radar observations. J. Geophys. Res., 114, D00A20, https://doi.org/10.1029/2008JD009790.

Morrison, H., and A. Gettelman, 2008: A new two-moment bulk stratiform cloud microphysics scheme in the Community Atmosphere Model, version 3 (CAM3). Part I: Description and numerical tests. J. Climate, 21, 3642-3659, https://doi.org/ 10.1175/2008JCLI2105.1.

Nam, C., S. Bony, J. L. Dufresne, and H. Chepfer, 2012: The "too few, too bright" tropical low-cloud problem in CMIP5 models. Geophys. Res. Lett., 39, L21801, https://doi.org/10.1029/ 2012GL053421.

Neale, R. B., and Coauthors, 2010: Description of the NCAR Community Atmosphere Model (CAM 5.0). NCAR Tech. Note NCAR/TN-486+STR, 268 pp.

Park, S., and C. S. Bretherton, 2009: The University of Washington shallow convection and moist turbulence schemes and their impact on climate simulations with the Community Atmosphere Model. J. Climate, 22, 3449-3469, https://doi.org/ 10.1175/2008JCLI2557.1.

,-- , and P. J. Rasch, 2014: Integrating cloud processes in the Community Atmosphere Model, version 5. J. Climate, 27, 6821-6856, https://doi.org/10.1175/JCLI-D-14-00087.1.

Pincus, R., S. Platnick, S. A. Ackerman, R. S. Hemler, and R. J. P. Hofmann, 2012: Reconciling simulated and observed views of clouds: MODIS, ISCCP, and the limits of instrument simulators. J. Climate, 25, 4699-4720, https://doi.org/10.1175/ JCLI-D-11-00267.1.

Platnick, S., and Coauthors, 2017: The MODIS cloud optical and microphysical products: Collection 6 updates and examples from Terra and Aqua. IEEE Trans. Geosci. Remote Sens., 55, 502-525, https://doi.org/10.1109/TGRS.2016.2610522.

Seifert, A., and K. Beheng, 2006: A two-moment cloud microphysics parameterization for mixed-phase clouds. Part 1: Model description. Meteor. Atmos. Phys., 92, 45-66, https:// doi.org/10.1007/s00703-005-0112-4.

Stephens, G. L., and Coauthors, 2002: The CloudSat mission and the A-Train. Bull. Amer. Meteor. Soc., 83, 1771-1790, https:// doi.org/10.1175/BAMS-83-12-1771.

Stevens, B., G. Vali, K. Comstock, R. Woods, M. C. Van Zanten, P. H. Austin, C. S. Bretherton, and D. H. Lenschow, 2005: Pockets of open cells and drizzle in marine stratocumulus. Bull. Amer. Meteor. Soc., 86, 51-57, https://doi.org/10.1175/BAMS-86-1-51.

Suzuki, K., G. Stephens, A. Bodas-Salcedo, M. Wang, J.-C. Golaz, T. Yokohata, and T. Koshiro, 2015: Evaluation of the warm rain formation process in global models with satellite observations. J. Atmos. Sci., 72, 3996-4014, https://doi.org/10.1175/ JAS-D-14-0265.1.

Vaughan, M. A., and Coauthors, 2009: Fully automated detection of cloud and aerosol layers in the CALIPSO lidar measurements. J. Atmos. Oceanic Technol., 26, 2034-2050, https://doi. org/10.1175/2009JTECHA1228.1.

Wang, M., and Coauthors, 2015: A multiscale modeling framework model (superparameterized CAM5) with a higher-order turbulence closure: Model description and low-cloud simulations. J. Adv. Model. Earth Syst., 7, 484-509, https://doi.org/10.1002/ 2014MS000375. 
Webb, M., C. Senior, S. Bony, and J. Morcrette, 2001: Combining ERBE and ISCCP data to assess clouds in the Hadley Centre, ECMWF and LMD atmospheric climate models. Climate Dyn., 17, 905-922, https://doi.org/10.1007/ s003820100157.

Winker, D. M., M. A. Vaughan, A. Omar, Y. Hu, K. A. Powell, Z. Liu, W. H. Hunt, and S. A. Young, 2009: Overview of the CALIPSO mission and CALIOP data processing algorithms. J. Atmos. Oceanic Technol., 26, 2310-2323, https://doi.org/ 10.1175/2009JTECHA1281.1.

, and Coauthors, 2010: The CALIPSO mission: A global 3D view of aerosols and clouds. Bull. Amer. Meteor. Soc., 91, 1211-1229, https://doi.org/10.1175/2010BAMS3009.1.

Wood, R., 2005: Drizzle in stratiform boundary layer clouds. Part I: Vertical and horizontal structure. J. Atmos. Sci., 62, 30113033, https://doi.org/10.1175/JAS3529.1.

, 2012: Stratocumulus clouds. Mon. Wea. Rev., 140, 2373-2423, https://doi.org/10.1175/MWR-D-11-00121.1.

— the marine boundary layer: An ARM mobile facility deployment. Bull. Amer. Meteor. Soc., 96, 419-440, https://doi. org/10.1175/BAMS-D-13-00180.1.

Xu, K.-M., and S. K. Krueger, 1991: Evaluation of cloudiness parameterizations using a cumulus ensemble model. Mon. Wea. Rev., 119, 342-367, https://doi.org/10.1175/1520-0493(1991) $119<0342$ :EOCPUA $>2.0$. CO 2 .

Zhang, G. J., and N. A. McFarlane, 1995: Sensitivity of climate simulations to the parameterization of cumulus convection in the Canadian Climate Centre general circulation model. Atmos.-Ocean, 33, 407-446, https://doi.org/10.1080/ 07055900.1995 .9649539 .

Zhang, K., and Coauthors, 2014: Technical Note: On the use of nudging for aerosol-climate model intercomparison studies.
Atmos. Chem. Phys., 14, 8631-8645, https://doi.org/10.5194/ acp-14-8631-2014.

Zhang, M. H., and Coauthors, 2005: Comparing clouds and their seasonal variations in 10 atmospheric general circulation models with satellite measurements. J. Geophys. Res., 110, D15S02, https://doi.org/10.1029/ 2004JD005021.

Zhang, Y., S. A. Klein, J. Boyle, and G. G. Mace, 2010: Evaluation of tropical cloud and precipitation statistics of Community Atmosphere Model version 3 using CloudSat and CALIPSO data. J. Geophys. Res., 115, D12205, https://doi.org/10.1029/ 2009JD012006.

Zhang, Z., and S. Platnick, 2011: An assessment of differences between cloud effective particle radius retrievals for marine water clouds from three MODIS spectral bands. J. Geophys. Res., 116, D20215, https://doi.org/10.1029/2011JD016216.

- A. S. Ackerman, G. Feingold, S. Platnick, R. Pincus, and H. Xue, 2012: Effects of cloud horizontal inhomogeneity and drizzle on remote sensing of cloud droplet effective radius: Case studies based on large-eddy simulations. J. Geophys. Res., 117, D19208, https://doi.org/10.1029/2012JD017655.

_ , and Coauthors, 2016: A framework based on 2-D Taylor expansion for quantifying the impacts of sub-pixel reflectance variance and covariance on cloud optical thickness and effective radius retrievals based on the bispectral method. J. Geophys. Res. Atmos., 121, 7007-7025, https://doi.org/ 10.1002/2016JD024837.

Zheng, X., S. A. Klein, H. Y. Ma, P. Bogenschutz, A. Gettelman, and V. E. Larson, 2016: Assessment of marine boundary layer cloud simulations in the CAM with CLUBB and updated microphysics scheme based on ARM observations from the Azores. J. Geophys. Res. Atmos., 121, 8472-8492, https://doi. org/10.1002/2016JD025274. 